\title{
Proline Functionalized Ui0-67 and UiO-68 Type Metal-Organic Frameworks Showing Reversed Diastereoselectivity in Aldol Addition Reactions
}

Christel Kutzscher, Georg Nickerl, Irena Senkovska, Volodymyr Bon, and Stefan Kaskel

\section{Supporting Information}

1. General methods, equipment and used parameters:..................................................... 2

2. General Characterization of Synthesized Materials ............................................................. 3

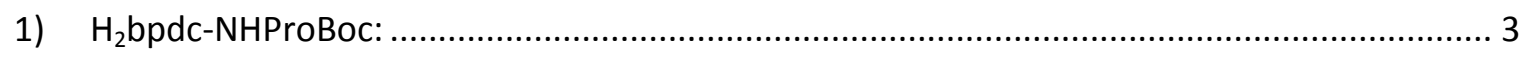

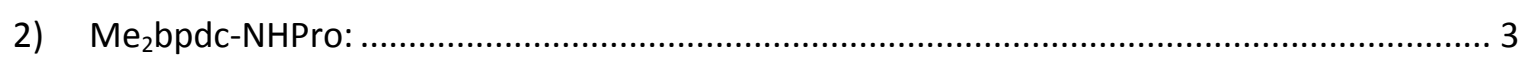

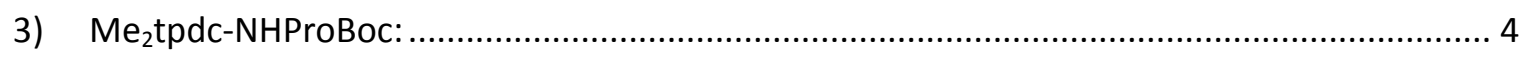

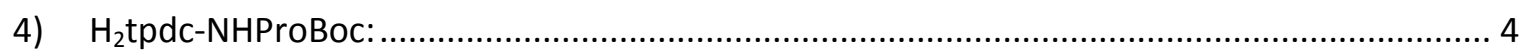

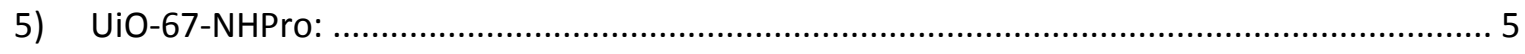

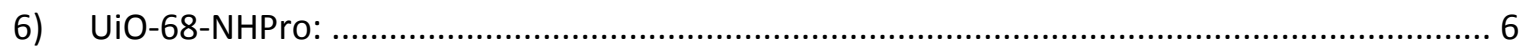

3. Investigations on Enantiomeric Purity of Proline Side Groups ......................................... 7

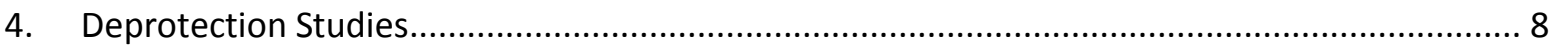

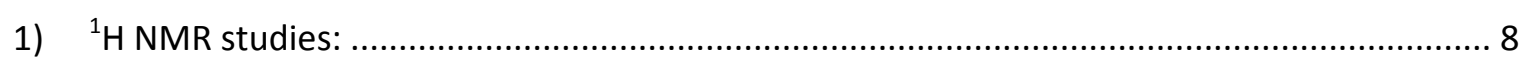

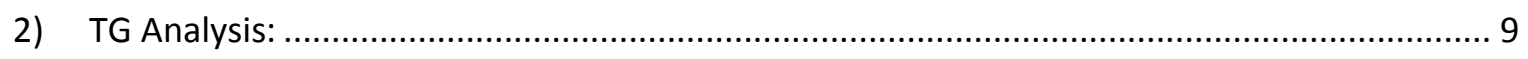

3) Identification of Deprotection Parameters: ........................................................... 10

5. Catalysis of Asymmetric Aldol Addition (4-nitrobenzaldehyde + cyclohexanone) .................... 12

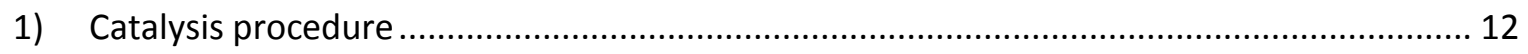

2) Development of HPLC analysis procedure for catalysis ............................................... 13

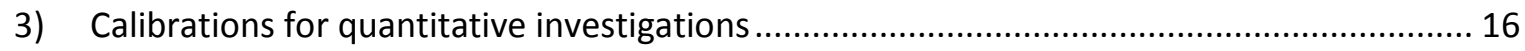

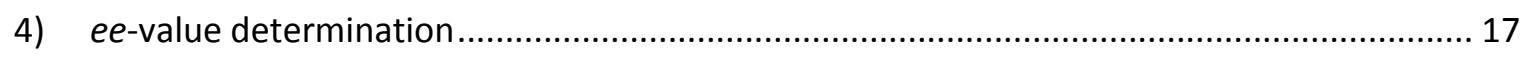

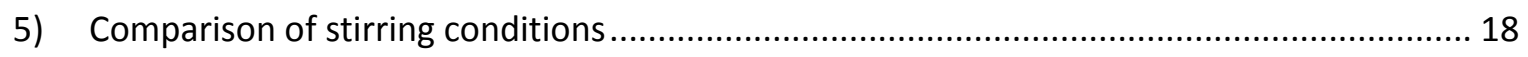

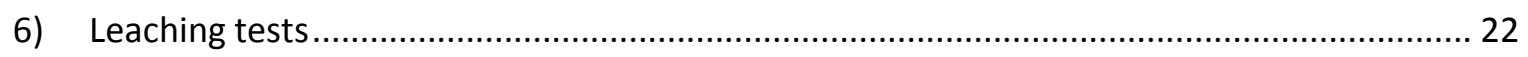

6. Crystallographic data for UiO-68-NHPro ................................................................... 23

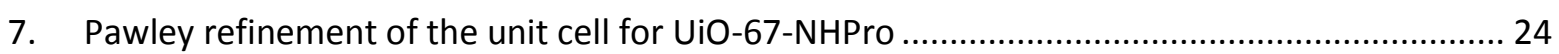

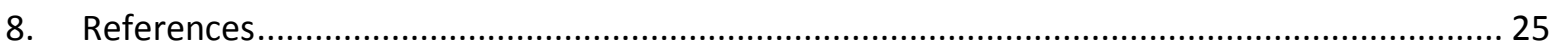




\section{General methods, equipment and used parameters:}

For powder X-ray diffraction analysis, Stoe StadiP X-ray diffractometer in transmission geometry was used. The sample was prepared as a flat base and irradiated by $\mathrm{CuK}_{\alpha, 1}$ radiation with a wavelength of $1.5405 \AA$ A. For measurements dried samples and solvent soaked samples were used. For nitrogen physisorption measurements at $77 \mathrm{~K}$, BELSORP MAX system from BEL JAPAN, INC. was used. The samples dried from ethanol were additionally activated in high vacuum over night at room temperature directly prior to the measurements. Samples activated by supercritical drying were evacuated at RT for 60 min prior to the measurements.

Thermogravimetric analysis was performed with the STA 409 system of NETZSCH company. The samples were heated up in air with a heating rate of $5 \mathrm{~K} / \mathrm{min}$ until mass constancy.

For infrared spectroscopic measurements VERTEX 70 system from BRUKER was used. Samples were grounded with potassium bromide and pressed into tablets. For descriptions of IR bands following abbreviations were used: s-strong, m-medium, w-weak, br-broad.

HPLC measurements were performed with and ELITE LACHROM System from VWR/HITACHI using a UV L2400 detector. For data evaluation EZCHROM ElITE software from AGILENT TECHNOLOGIES was applied. Depending on the separation problem, the chiral column CHIRACEL IA, $250 \mathrm{~mm}$, from DAICEL or LICHROSPHER ${ }^{\circledR} 100$ RP-18 column, 250 mm, from LICHROCART ${ }^{\circledR}$ MERCK MILLIPORE was used. Further specifications for separation parameters are given at the corresponding synthesis procedure descriptions of the analytes in ESI. HPLC measurements for ee-value determination of aldol adducts were performed at Organic Chemistry I department at Technische Universität Dresden using Lux Amylose I, 5 um column. For details see chapter 5.4.

REM measurements were performed using measurement system SU 8020 from HITACHI. The images were made with voltages of 2-7 kV. The applied enlargements are displayed on the individual images.

For elemental analysis EA 3000 EURO VECTOR CHNSO system from HEKATECH was used. Results are given in mass percent.

Liquid NMR spectra were collected on DRX-500 or ASP-600-P spectrometer from BRUKER. Before

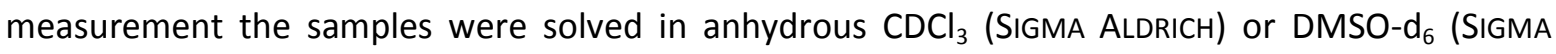
ALDRICH). For further evaluation of the spectra following abbreviations were used: $s-$ singlet, $d-$ doublet, $\mathrm{dd}$ - dual doublet, $\mathrm{t}$ - triplet, $\mathrm{m}$ - multiplet.

UV/VIS measurements were performed using UV-1650PC from SHIMADZU. For data evaluation UVProbe 2.10 software was used. 


\section{General Characterization of Synthesized Materials}

\section{1) $\mathrm{H}_{2}$ bpdc-NHProBoc:}

Linker was synthesized and characterized, as described in our previous publication (Kutzscher et al. $\left.{ }^{1}\right)$.

\section{2) $\mathrm{Me}_{2}$ bpdc-NHPro:}

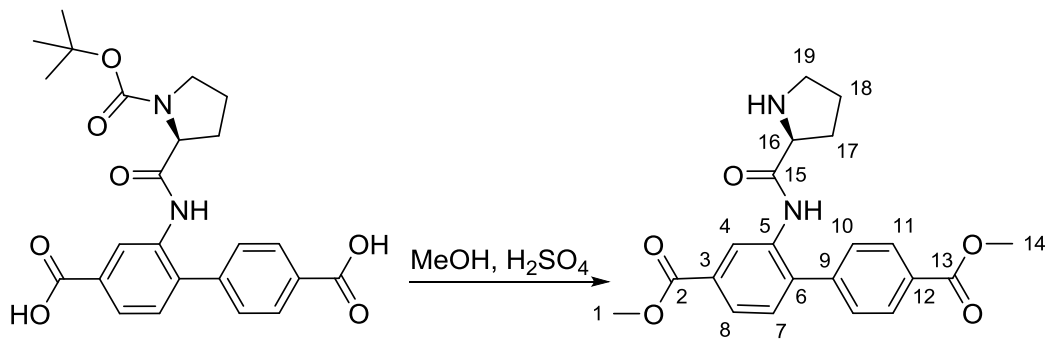

Linker $\mathrm{H}_{2}$ bpdc-NHProBoc (500 mg, $1.1 \mathrm{mmol}$ ) was solved in $15 \mathrm{ml}$ of a mixture of methanol and sulfuric acid ( $\mathrm{MeOH} / \mathrm{H}_{2} \mathrm{SO}_{4}$ (conc.), 99/1). The solution was heated up to $70{ }^{\circ} \mathrm{C}$ and stirred under reflux for $18 \mathrm{~h}$. The organic solvent was evaporated and the residual mixture was neutralized with saturated aqueous sodium bicarbonate solution. The aqueous phase was extracted with DCM $(4 \times 20 \mathrm{ml})$ and the resulting organic phase was dried with magnesium sulfate. The solvent was evaporated and dried in high vacuum in order to obtain an orange oil.

${ }^{1} \mathrm{H}-\mathrm{NMR}\left(\mathrm{CDCl}_{3}\right): \delta(\mathrm{ppm})=1.57-1.77(\mathrm{~m}, 2 \mathrm{H}, 18-\mathrm{H}), 1.95-2.08(\mathrm{~m}, 1 \mathrm{H}, 19 \mathrm{a}-\mathrm{H}), 2.10-2.22(\mathrm{~m}, 1 \mathrm{H}$, $19 b-H), 2.62-2.74(m, 1 H, 17 a-H), 2.88-2.98(m, 1 H, 17 b-H), 3.85-3.94(m, 1 H, 16-H), 3.94-3.97$ (m, $6 \mathrm{H}, 1-\mathrm{H}+14-\mathrm{H}), 5.31$ (s, $1 \mathrm{H}, \mathrm{NH}$-proline), 7.34 (d, 1H, Aryl-H), 7.48 (d, 2H, Aryl-H), 7.88 (d, 1H, Aryl$H), 8.15(\mathrm{~d}, 2 \mathrm{H}$, Aryl-H), 8.97 (m, 1H, Aryl-H).

${ }^{13}$ C-NMR $\left(\mathrm{CDCl}_{3}\right): \delta(\mathrm{ppm})=25.84\left(\mathrm{CH}_{2}-18\right), 30.64\left(\mathrm{CH}_{2}-19\right), 47.03\left(\mathrm{CH}_{2}-19\right), 52.25+52.30\left(\mathrm{CH}_{3}-1+\right.$ $\left.\mathrm{CH}_{3}-14\right), 60.77$ (CH-16), 122.55 (CH-Aryl), 125.58 (CH-Aryl), 129.17 (CH-Aryl + CH-Aryl), 129.79 (CAryl), 129.95 (CH-Aryl), 130.70 (C-Aryl), 134.77 (C-Aryl), 136.29 (C-Aryl), 142.42 (C-Aryl), $166.62+$ 166.67 (COO-2 + COO-13), 172.76 (CO-15).

IR (ATR): v $\left(\mathrm{cm}^{-1}\right)=3362(\mathrm{~b}, \mathrm{NH}$-amide), $2951(\mathrm{w}+\mathrm{b}), 2871(\mathrm{w}+\mathrm{b}), 1715$ (vs, C=0), $1687(\mathrm{~m}), 1525$ (m), 1505 (m), 1421 (m), 1275 (vs), 1243 (s), 1101 (vs), 761 (vs, CH-Aryl). 


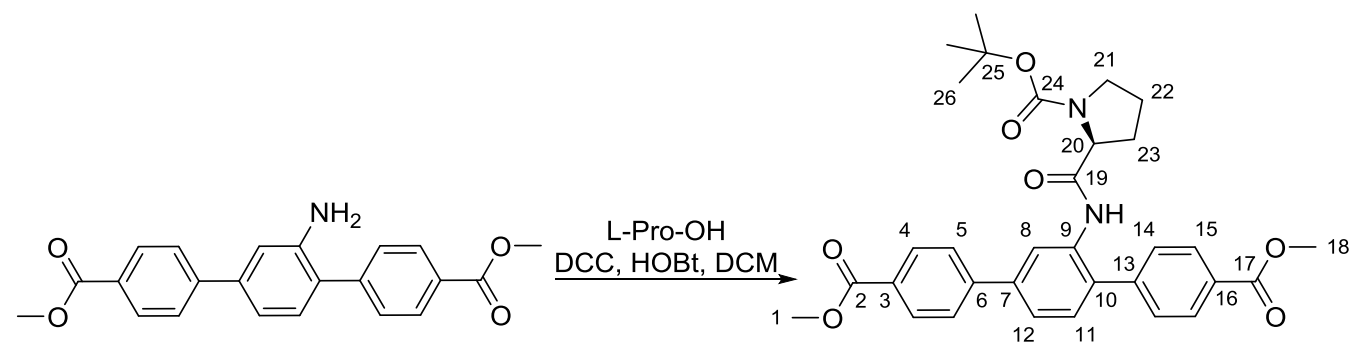

${ }^{1} \mathrm{H}-\mathrm{NMR}\left(\mathrm{CDCl}_{3}\right): \delta(\mathrm{ppm})=1.35(\mathrm{~s}, 9 \mathrm{H}, 26-\mathrm{H}), 1.57-1.99\left(\right.$ broad $\left.\mathrm{m}, 2 \mathrm{CH}_{2}, 22+23-\mathrm{H}\right), 3.10-3.30(\mathrm{~m}$, $2 \mathrm{H}, 20-\mathrm{H}), 3.92-4.01(\mathrm{~m}, 6 \mathrm{H}, 1+18-\mathrm{H}), 4.19-4.39(\mathrm{~m}, 1 \mathrm{H}, 20-\mathrm{H}), 7.33-7.38(\mathrm{~m}, 1 \mathrm{H}$, Aryl-H), 7.44-7.53 (m, 3H, Aryl-H), 7.72 (d, 2H, Aryl-H), 8.09-8.15 (m, 2H, Aryl-H), 8.16-8.22 (m, 2H, Aryl-H), 8.63-8.79 (m, $1 \mathrm{H}$, Aryl-H).

IR: $v\left(\mathrm{~cm}^{-1}\right)=3327(\mathrm{w}+\mathrm{b}), 2971+2963+2848(\mathrm{~m}), 1713+1696+1670(\mathrm{~s}), 1611(\mathrm{~m}), 1560(\mathrm{~s}), 1445$ $(\mathrm{m}), 1403(\mathrm{~s}), 1276(\mathrm{~s}), 1161+1110(\mathrm{~m}), 771(\mathrm{~m})$.

Elemental Analysis: $\mathrm{C}_{32} \mathrm{H}_{34} \mathrm{~N}_{2} \mathrm{O}_{7} \quad$ calculated: $\mathrm{C} 68.8 \%, \mathrm{H} 6.13 \%, \mathrm{~N} 5.01 \%$; found: C $68.59 \%$, H $6.42 \%$, N 5.13\%.

Thermogravimetric Analysis: mass loss is listed in weight percent.

1. Step: $-20.48 \%$ (decomposition of Boc group), 2.-5. Step: $-79.52 \%$, residual mass: $0.00 \%$.

\section{4) $\mathrm{H}_{2}$ tpdc-NHProBoc:}

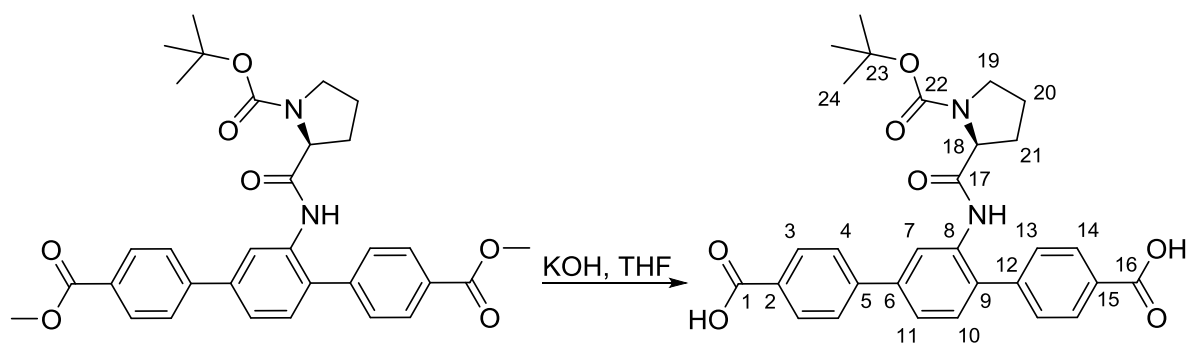

${ }^{1} \mathrm{H}-\mathrm{NMR}\left(D M S O-d_{6}\right): \delta(\mathrm{ppm})=1.30-1.39(\mathrm{~m}, 9 \mathrm{H}, 24-\mathrm{H}), 1.67-1.78\left(\mathrm{~m}, 3 \mathrm{H}, 20-\mathrm{H}+21_{1}-\mathrm{H}\right), 1.98-2.13$ $\left(\mathrm{m}, 1 \mathrm{H}, 21_{2}-\mathrm{H}\right), 3.1-3.7(\mathrm{~m}$, water amount covers signal of $19-\mathrm{H}$, identified by 2D-NMR), 4.12-4.21 (m, 1H, 18-H), 7.46-7.55 (m, 2H, Aryl-H), 7.55-7.61 (m, 1H, Aryl-H), 7.65-7.71 (m, 1H, Aryl-H), 7.74$7.83(\mathrm{~m}, 2 \mathrm{H}$, Aryl-H), 7.97-8.04 (m, 2H, Aryl-H), 8.04-8.09 (m, 2H, Aryl-H), 9.32-9-57 (m, extensive splitted signal, $1 \mathrm{H}, 7-\mathrm{H})$. 
${ }^{13} \mathrm{C}-\mathrm{NMR}\left(D M S O-d_{6}\right): \quad \delta(\mathrm{ppm})=23.10\left(\mathrm{CH}_{2}-20\right), 28.09\left(\mathrm{CH}_{3}-24\right), 30.58\left(\mathrm{CH}_{2}-21\right), 46.53\left(\mathrm{CH}_{2}-19\right)$, 59.99 (CH-18), 78.40 (C-23), 124.42 ( $\left.C_{\text {aryl }}-10\right), 124.50$ ( $\left.C_{\text {aryl }}-7+9\right), 126.57\left(C_{\text {aryy }}\right), 128.89\left(2 C_{\text {aryl }}\right), 129.41$ $\left(2 C_{\text {aryy }}\right), 130.20\left(2 C_{\text {ary }}\right), 131.12$ ( $\left.C_{\text {ary }}-11\right), 134.44\left(C_{\text {aryl }}-12\right), 135.42\left(C_{\text {aryl }}-6\right), 139.11\left(\left.C_{\text {ary }}\right|^{-5}\right), 142.58$

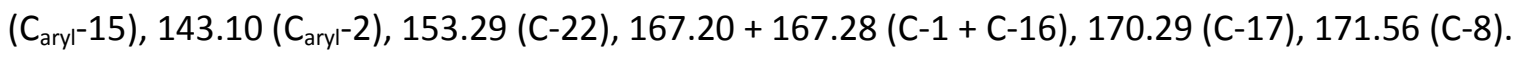

IR: $v\left(\mathrm{~cm}^{-1}\right)=2975+2925(w+b), 2658+2539(w+b), 1691(s+b), 1606(m), 1424(m+b)$, $1280(m+b), 1161(m+b), 767(m)$.

Thermogravimetric Analysis: mass loss is listed in weight percent.

1. Step: $-1.71 \%$, 2.-5. Step: - $97.29 \%$, residual mass: $1.00 \%$.

Elemental Analysis: $\mathrm{C}_{30} \mathrm{H}_{30} \mathrm{~N}_{2} \mathrm{O}_{7} \quad$ calculated: $\mathrm{C} 66.78 \%, \mathrm{H} 5.79 \%, \mathrm{~N} 5.19 \%$ found: C 66.19\%, H 6.04\%, N $5.32 \%$.

Thermal analysis and ${ }^{1} \mathrm{H}-\mathrm{NMR}$ showed high water content in the sample. Quantitative evaluation by TG showed water content of 50 wt\%. Recalculation of theoretical EA values proved this assumption.

\section{5) UiO-67-NHPro:}

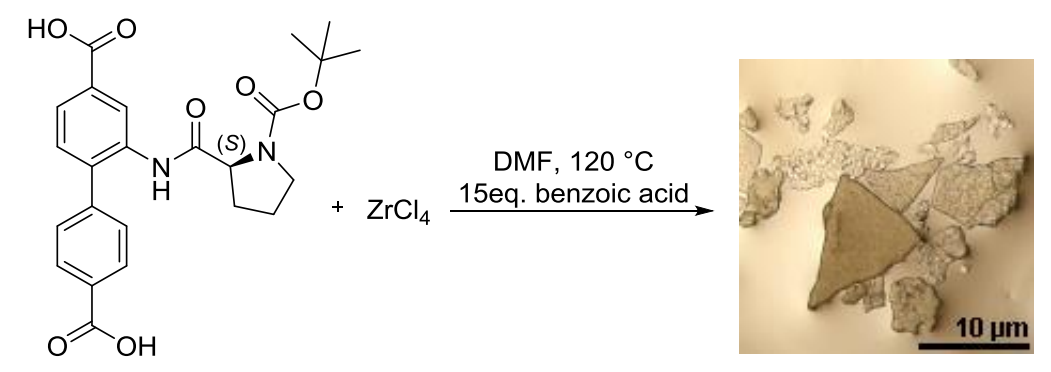

${ }^{1} \mathrm{H}-\mathrm{NMR}\left(D M S O-d_{6}+D C l\right): \delta(\mathrm{ppm})=1.28-1.38(\mathrm{~m}, 1 \mathrm{H}, 16-\mathrm{H}), 1.39-1.47(\mathrm{~m}, 1 \mathrm{H}, 17-\mathrm{H}), 1.48-1.58(\mathrm{~m}$, $1 \mathrm{H}, 16-\mathrm{H}), 1.89-1.98(\mathrm{~m}, 1 \mathrm{H}, 17-\mathrm{H}), 2.82-2.96(\mathrm{~m}, 2 \mathrm{H}, 15-\mathrm{H}), 3.98-4.06(\mathrm{~m}, 1 \mathrm{H}, 14-\mathrm{H}), 7.13-7.20(\mathrm{~m}$, $2 \mathrm{H}, 9-\mathrm{H}), 7.20-7.25(\mathrm{~m}, 1 \mathrm{H}, 7-\mathrm{H}), 7.60-7.68(\mathrm{~m}, 3 \mathrm{H}, 6-\mathrm{H}$ und 10-H), 7-83-7.86 (m, 1H, 3-H).

IR: $v\left(\mathrm{~cm}^{-1}\right)=3227+2927(\mathrm{~m}+\mathrm{b}), 1659(\mathrm{~s}), 1595(\mathrm{~s}), 1550(\mathrm{~s}), 1404(\mathrm{~s}+\mathrm{b}), 1095(\mathrm{w}), 773(\mathrm{~m}), 664$ (m), $451(w)$.

\section{Thermogravimetric Analysis:}

1. Step: $-7.67 \%$, 2. - 3. Step: $-68.69 \%$, residual mass: $23.64 \%$.

Elemental Analysis: $\mathrm{C}_{127} \mathrm{H}_{134.5} \mathrm{~N}_{11} \mathrm{O}_{50.5} \mathrm{Zr}_{6}$ calculated: C 48.11\%, H 4.28\%, N 4.86\% found: C $47.97 \%, \mathrm{H} 4.33 \%, \mathrm{~N} 4.86 \%$. 
The chemical composition based on of TG and EA is: $\mathrm{Zr}_{6} \mathrm{O}_{4}(\mathrm{OH})_{4}(\mathrm{bpdc}-$ NHPro $)_{5.5}(\text { benz })_{2.5}\left(\mathrm{H}_{2} \mathrm{O}\right)_{7.5}(\mathrm{EtOH})_{2.5}$. The sample should contain defects, induced by utilization of modulator (benzoic acid (benz)) and caused by high steric demand of chiral functionalized linker.

6) UiO-68-NHPro:
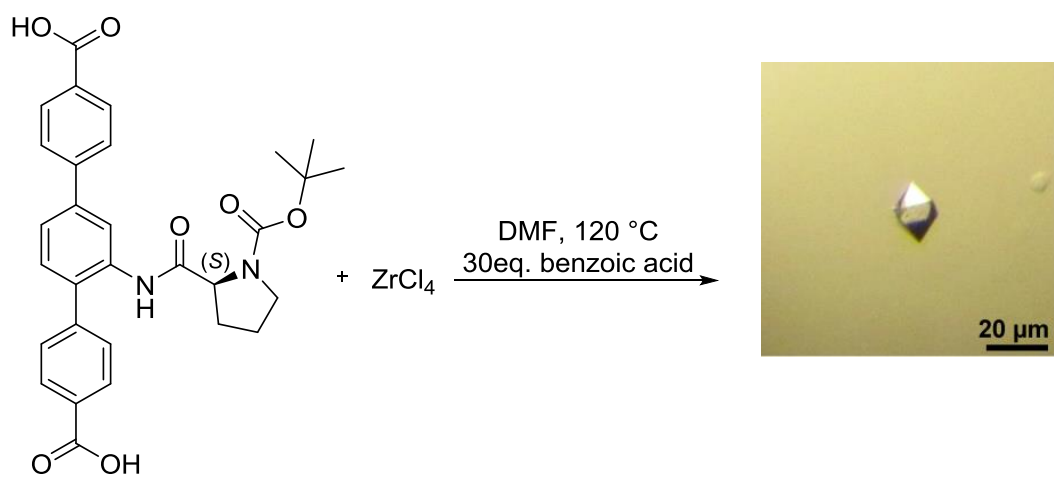

IR: $v\left(\mathrm{~cm}^{-1}\right)=3286+2977(\mathrm{~m}+\mathrm{b}), 1673(\mathrm{~m}), 1600+1550(\mathrm{~m}), 1410(\mathrm{~s}), 1183(\mathrm{~s}), 1009(\mathrm{~s}), 782(\mathrm{~m})$, $710(\mathrm{~m}), 451(\mathrm{~m})$.

\section{Thermogravimetric Analysis:}

1. Step: $-5.02 \%$ (water), 2. - 4. Step: $-74.77 \%$, residual mass: $20.23 \%$.

Elemental Analysis: $\mathrm{C}_{135.5} \mathrm{H}_{129.5} \mathrm{~N}_{10} \mathrm{O}_{45} \mathrm{Zr}_{6}$

calculated: C 51.41\%, H 4.12\%, N 4.43\%

found: C 49.93\%, H 3.56\%, N 4.15\%.

The chemical composition based on of TG and EA is: $\mathrm{Zr}_{6} \mathrm{O}_{4}(\mathrm{OH})_{4}(\text { tpdc-NHPro })_{5}(\text { benz })_{1.5}\left(\mathrm{H}_{2} \mathrm{O}\right)_{9}$. The sample should contain defects, induced by utilization of modulator (benzoic acid (benz)) and caused by high steric demand of chiral functionalized linker. 


\section{Investigations on Enantiomeric Purity of Proline Side Groups}

Studies on enantiomeric purity of the $\mathrm{H}_{2}$ bpdc-NHProBoc linker are already reported in ref. 1 . For determination of enantiomeric excess (ee), chiral separation with HPLC was performed, using chiral column ChIRALPAK IA (DAICEL). A method could be developed allowing direct measurement of the free acid linker $\mathrm{H}_{2}$ bpdc-NHProBoc without further esterification. This procedure allowed us to measure the pure linker $\mathrm{H}_{2}$ bpdc-NHProBoc directly after four step synthesis, resulting in ee of $99 \%$. Furthermore, the enantiomeric purity of the linker was investigated after several thermal treatment procedures. Therefore, the linker was solved in DMF (synthesis solvent of typical MOF synthesis) and thermally treated at 100,120 , and $140^{\circ} \mathrm{C}$ for several days.

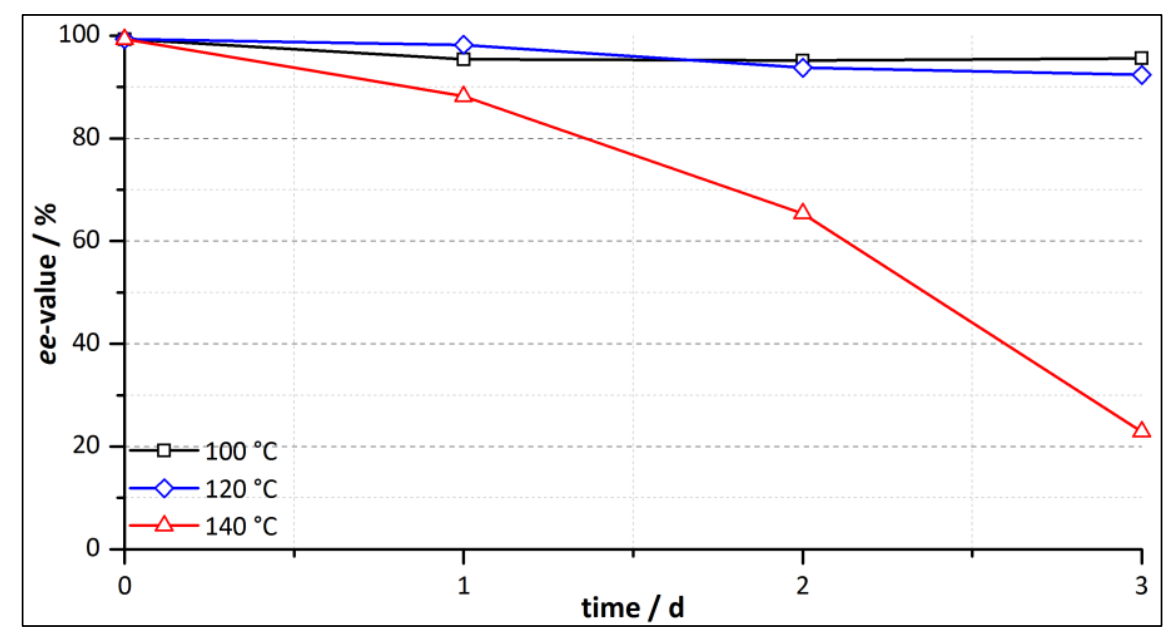

Figure S.1 Ee-value evolution of linker $\mathrm{H}_{2}$ bpdc-NHProBoc by thermal treatment at 100,120 and $140^{\circ} \mathrm{C}$ for $1-3$ days determined by chiral HPLC.

Figure S. 1 shows constantly high ee-values during the treatment at 100 and $120^{\circ} \mathrm{C}$ even after 3 days. At $140{ }^{\circ} \mathrm{C}$, ee-values decreases with the time up to complete racemization. Consequently, at synthesis temperature of $120^{\circ} \mathrm{C}$ for UiO-67-NHPro only low influence of the temperature on enantiomeric purity of the $\mathrm{H}_{2}$ bpdc-NHProBoc linker is expected. To prove this assumption additional measurements of the linker purity after the MOF synthesis are needed. Unfortunately, linker deprotection taking place during the MOF synthesis precludes chiral HPLC analysis due to the formation of free amine group of proline. The established separation method cannot be applied to the deprotected $\mathrm{H}_{2}$ bpdc-NHPro linker.

Investigations on enantiomeric purity of $\mathrm{H}_{2}$ tpdc-NHProBoc were hindered, due to the low solubility of the linker in solvents suitable for HPLC analysis.

Nevertheless, chemical similarity of the side groups of $\mathrm{H}_{2}$ bpdc-NHProBoc and $\mathrm{H}_{2}$ tpdc-NHProBoc allow the assumption of similar response to the thermal treatment behavior of both linkers. The 
main step in linker synthesis is the coupling with Boc-L-proline, which takes place at mild conditions, same for both linkers. Furthermore, MOF syntheses were performed at the same temperature, utilizing the same reagents, and during the same reaction time.

For further details of ee-value determination of $\mathrm{H}_{2}$ bpdc-NHProBoc consult ref. 1.

\section{Deprotection Studies}

\section{1) ${ }^{1}$ H NMR studies:}

For liquid ${ }^{1} \mathrm{H}$ NMR studies dried MOF sample was placed into $600 \mu \mathrm{LMSO}-\mathrm{d}_{6}$ and three drops of $\mathrm{DCl}$ were added to destroy the framework. The obtained solution was measured using a $500 \mathrm{MHz}$ spectrometer. The obtained spectra were compared with the spectrum of the linker bearing protected proline group, measured in DMSO- $\mathrm{d}_{6}+\mathrm{DCl}$ mixture. No siganls for Boc protecting groups could be identified for UiO-67-NHPro and UiO-68-NHPro (see Figure S.2 - S.3).

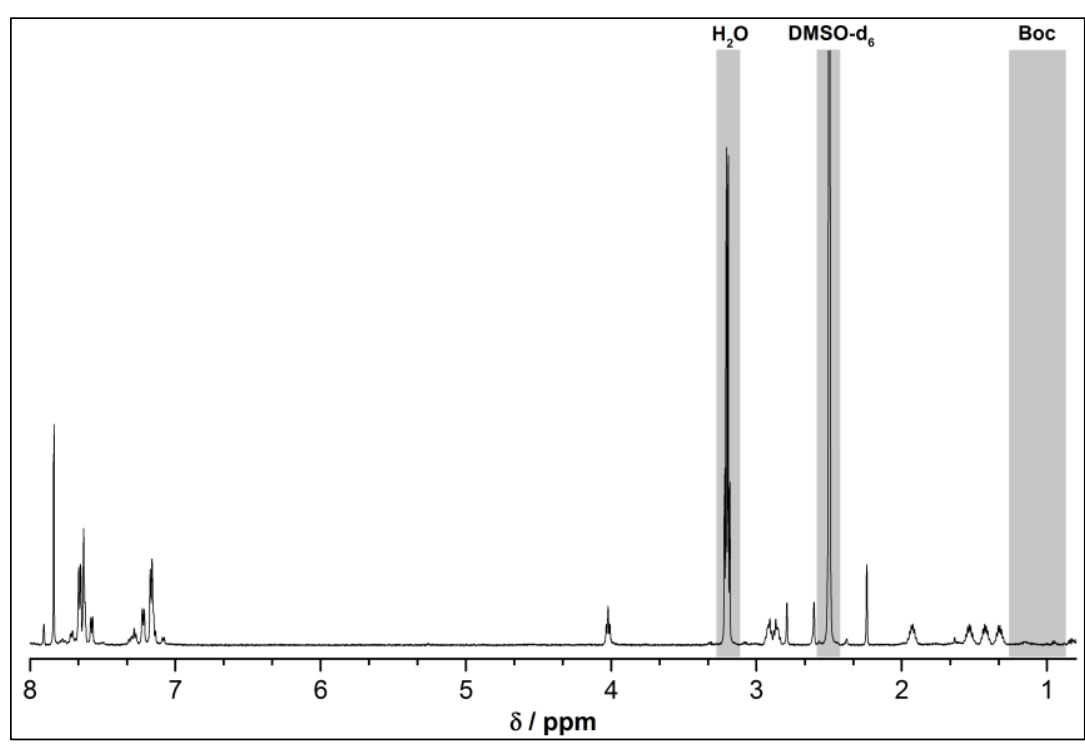

Figure S.2 Liquid ${ }^{1} \mathrm{H}$ NMR spectrum of UiO-67-NHPro decomposed by $\mathrm{DCl}$ in DMSO- $\mathrm{d}_{6}$. The spectrum shows no signals for the Boc protecting group expected in region between $0.8-1.5 \mathrm{ppm}$. 


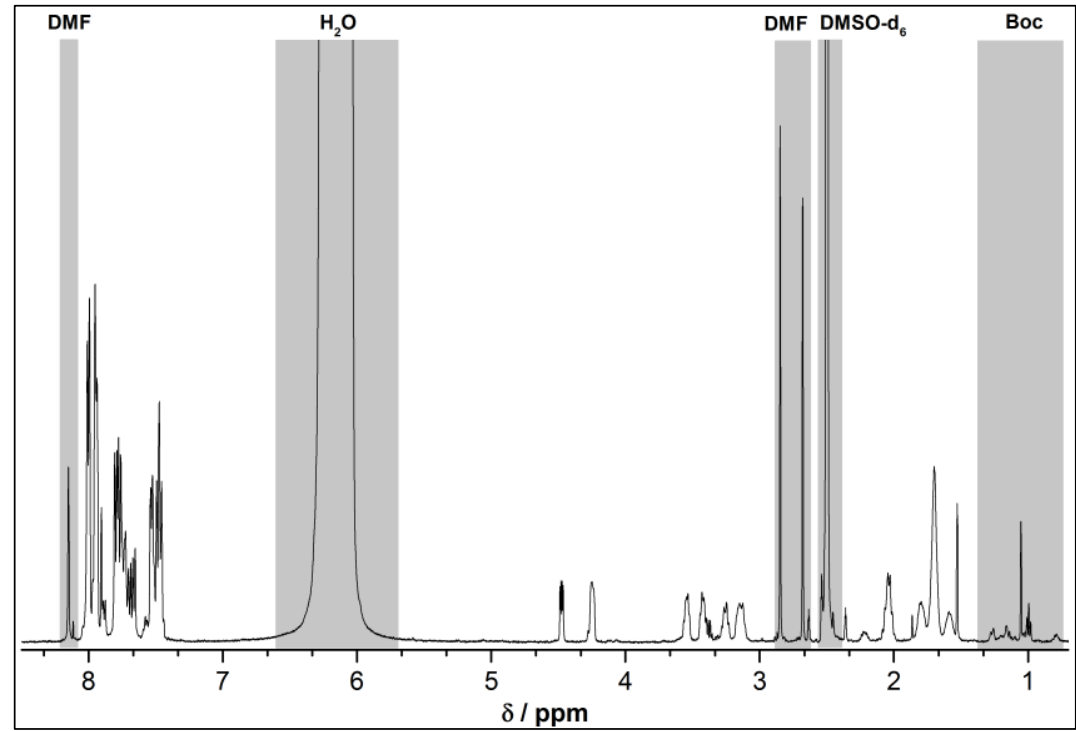

Figure S.3 Liquid ${ }^{1} \mathrm{H}$ NMR spectrum of UiO-68-NHPro, decomposed by $\mathrm{DCl}$ in DMSO- $\mathrm{d}_{6}$. The spectrum shows no signals for the Boc protecting group expected in region between $0.8-1.5$ ppm.

\section{2) TG Analysis:}

Thermogravimetric (TG) analysis was performed for activated UiO-67-NHPro and UiO-68-NHPro samples and corresponding $\mathrm{H}_{2}$ bpdc-NHProBoc and $\mathrm{H}_{2}$ tpdc-NHProBoc linkers (Figure S.4). The TG curves of both linkers show significant mass loss in the region between 160 and $250{ }^{\circ} \mathrm{C}$, corresponding to the elimination of Boc group. Curves of the MOFs show no mass loss in the same temperature region, corresponding to Boc deprotection, confirming the results of ${ }^{1} \mathrm{H} N M R$.

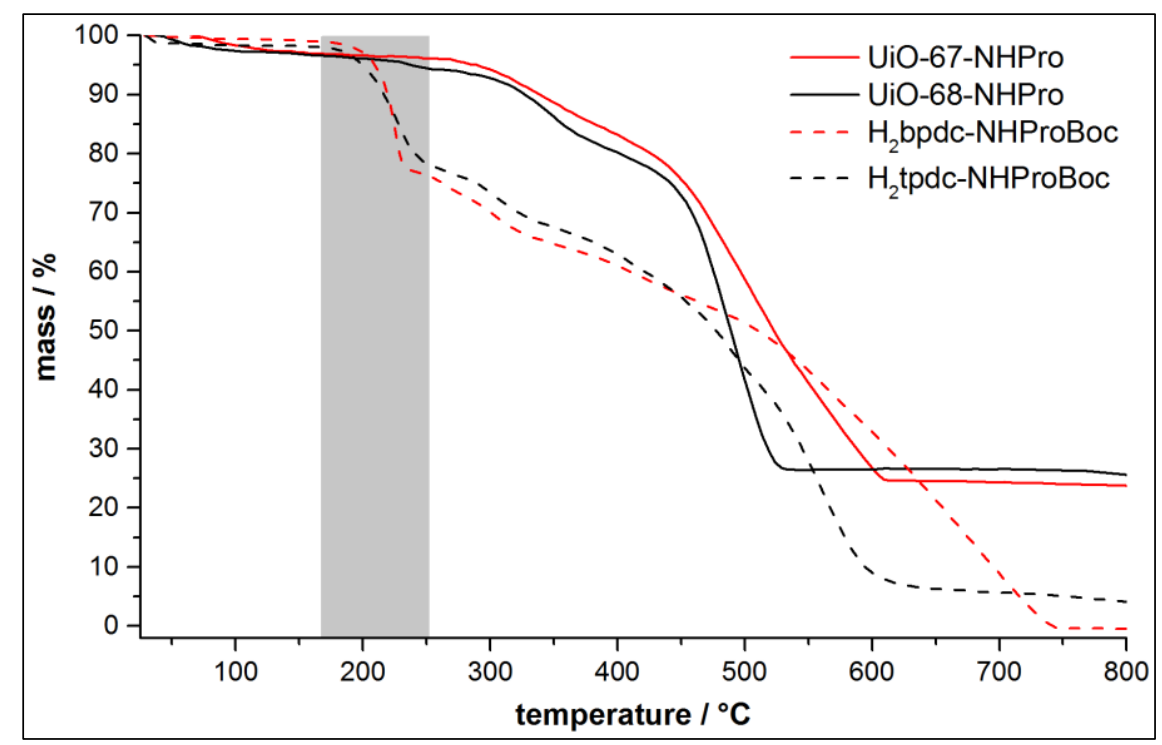

Figure S.4 Thermogravimetric analysis of UiO-67-NHPro, UiO-68-NHPro and corresponding linkers $\mathrm{H}_{2}$ bpdc-NHProBoc and $\mathrm{H}_{2}$ tpdc-NHProBoc. The gray marked area illustrates typical region for thermal Boc deprotection. 


\section{3) Identification of Deprotection Parameters:}

Several parameters of MOF synthesis were tested to identify trigger for deprotection during the synthesis of UiO-67-NHPro and UiO-68-NHPro. All investigations were performed with $\mathrm{H}_{2}$ bpdcNHProBoc as model system.

- Thermal deprotection of the Boc group was tested using $\mathrm{H}_{2}$ bpdc-NHProBoc in pure DMF (the concentration was chosen in analogy to MOF synthesis). $\mathrm{H}_{2}$ bpdc-NHProBoc (306 mg, $0.67 \mathrm{mmol}$ ) was solved in DMF $(50 \mathrm{ml})$ and the solution was divided into 7 parts and thermally treated at $120^{\circ} \mathrm{C}$ for $1-7$ days. After each $24 \mathrm{~h}$ one sample was cooled down to room temperature and investigated by HPLC with following parameters: column: CHIRALPAK IA (DAICEL), mobile phase: 4:1 methanol/water (+0.05\% trifluoroacetic acid), flow: $0.2 \mathrm{ml} \mathrm{min}^{-1}$, $\mathrm{t}_{R}(\mathrm{~S}$-enantiomer $)=23.3 \mathrm{~min}$. The measurements showed constant concentration of $\mathrm{H}_{2} \mathrm{bpdc}-$ NHProBoc after 7 days of thermal treatment, demonstrating no deprotection at these conditions.

- Deprotection by DMF derivatives can also be ruled out by the thermal experiments described before. The applied DMF is in pro analysi (p.a.) purity. Consequently low, non-defined amount of water is in the solvent. During heating a degradation of DMF is expected. Resulting derivatives might influence the deprotection process, but the results of the experiments showed no deprotection. Therefore, deprotection by DMF derivatives, like amines, should be excluded in this context.

- $\mathrm{HCl}$ induced deprotection was tested, due to in situ $\mathrm{HCl}$ formation in MOF synthesis mixture by reaction of $\mathrm{ZrCl}_{4}$ with water ( 1 eq. $\mathrm{ZrCl}_{4}$ can produce 4 eq. $\mathrm{HCl}$ ). Therefore $\mathrm{H}_{2}$ bpdc-NHProBoc (23 mg, $0.05 \mathrm{mmol})$ and $18 \mu \mathrm{L} \mathrm{HCl}(37 \mathrm{wt} . \%, 0.21 \mathrm{mmol}$ ) were dissolved in DMF $(2 \mathrm{~mL})$. The solution was heated up to $120^{\circ} \mathrm{C}$ for 4 days. The mixture was analyzed by liquid ${ }^{1} \mathrm{H}$ NMR in DMF- $d_{7}$. The appearance of the signals corresponding to the Boc group in the spectrum confirm that the Boc group is still intact after treatment with $\mathrm{HCl}$.

- Zirconium induced deprotection was investigated using the methyl ester $\mathrm{Me}_{2}$ bpdc-NHProBoc in combination with $\mathrm{ZrCl}_{4}$. The ester was used instead of carboxylic acid to prevent MOF formation. Concentrations of the chemicals were chosen in analogy to the MOF synthesis. $\mathrm{Me}_{2}$ bpdc-NHProBoc $(61.5 \mathrm{mg}, 0.13 \mathrm{mmol})$ and $\mathrm{ZrCl}_{4}(30 \mathrm{mg}, 0.13 \mathrm{mmol})$ were dissolved in DMF $(5 \mathrm{~mL})$. The solution was portioned into 4 samples. The samples were thermally treated at $120^{\circ} \mathrm{C}$. The solutions showed an increasing turbidity after 48 hours. After each $24 \mathrm{~h}$ one sample was cooled down to room temperature. For HPLC-investigations, the solution was filtered with Celite ${ }^{\circledR}$ using ethyl acetate for washing to remove metal salts from the mixture. The ethyl acetate was evaporated at $40^{\circ} \mathrm{C}$. The concentrated solution was measured by chiral HPLC using 
following parameters: column: CHIRALPAK IA (DAICEL), wavelength: $254 \mathrm{~nm}$, mobile phase: $n$ hexane/iso-propanol (95/5), flow: $1.5 \mathrm{ml} \mathrm{min}^{-1}, \mathrm{t}_{R}\left(\mathrm{Me}_{2}\right.$ bpdc-NHProBoc) $=16.8 \mathrm{~min}$. Figure S.5 shows HPLC chromatograms, indicating a deprotection of $\mathrm{Me}_{2}$ bpdc-NHProBoc already after 1 day of thermal treatment with the signal at $29.8 \mathrm{~min}$ for $\mathrm{Me}_{2}$ bpdc-NHPro. The area of the signal is decreasing during the next three days by $36 \%$, which can be explained by precipitation of a coordination compound formed by the deprotected ester and zirconium ions. Obviously, the product has low solubility in DMF, and causes turbidity of the investigated mixture.

Further signals in chromatograms are not assigned. A transformation of the linker ester into carboxylic acid can be excluded, since comparison of chromatograms showed no characteristic signals.

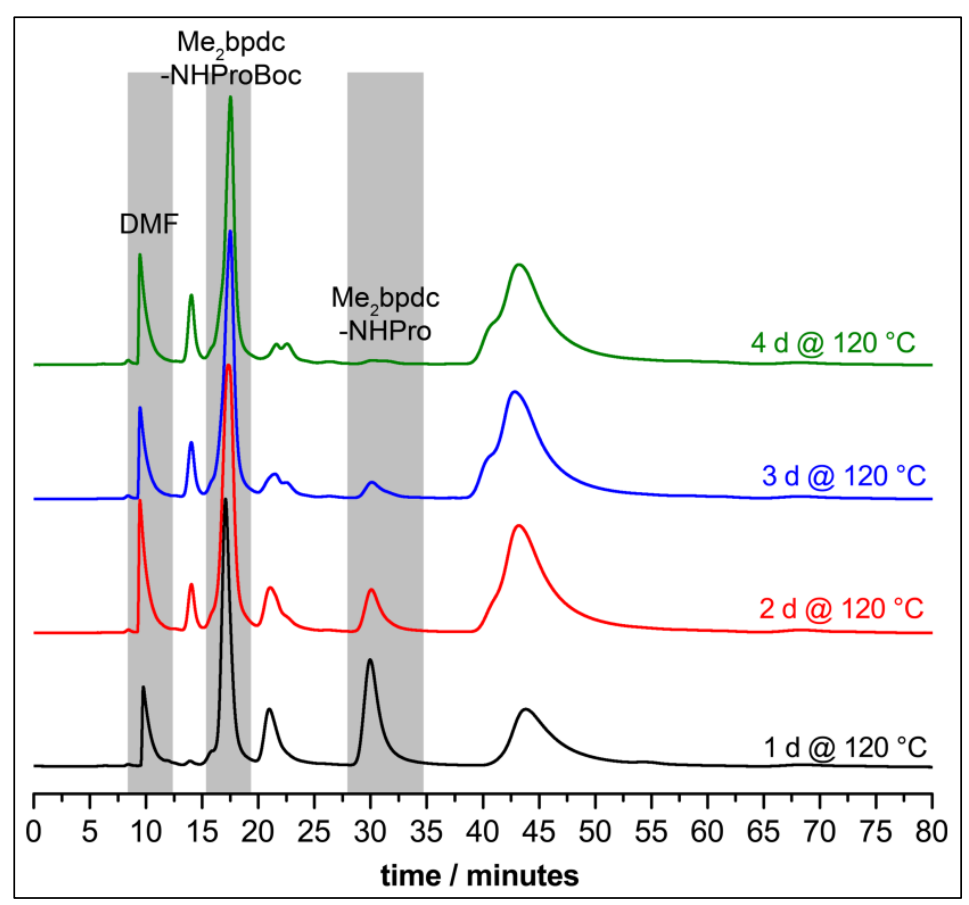

Figure S.5 HPLC chromatograms of linker ester ( $\mathrm{Me}_{2}$ bpdc-NHProBoc) and zirconium, heated in DMF for 1 (black), 2 (red), 3 (blue) and 4 (green) days. 


\section{Catalysis of Asymmetric Aldol Addition (4-nitrobenzaldehyde + cyclohexanone)}

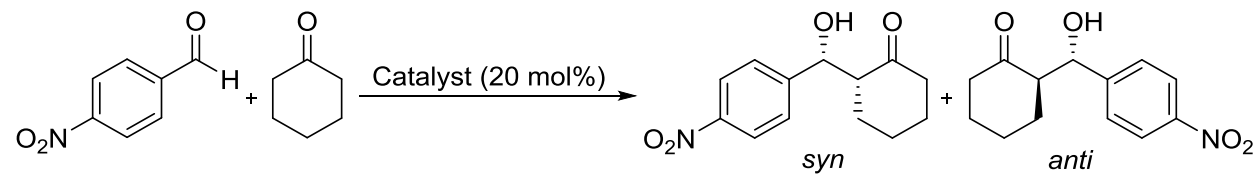

\section{1) Catalysis procedure}

Unless otherwise specified, standard reaction conditions were used.

Catalysis with UiO-67-NHPro: Two batches of UiO-67-NHPro (approximately $100 \mathrm{mg}, 0.21 \mathrm{mmol}$ regarding to amount of proline groups) were combined and washed with ethanol $(3 \times 5 \mathrm{ml})$ and the supernatant solvent was removed. The material was transferred in a screwed glass vial $(32 \times 11.6 \mathrm{~mm})$, which was placed in a culture tube $(16 \times 100 \mathrm{~mm})$. On top of the small glass tube, a stirring bar was placed. A solution of 4-nitrobenzaldehyde $(151 \mathrm{mg}, 1 \mathrm{mmol}$ ) in ethanol (dry, $5 \mathrm{ml}$ ) was added to UiO-67-NHPro. After short mixing time, cyclohexanone (982 mg, $10 \mathrm{mmol}$ ) was added dropwise. The solution was stirred at $40{ }^{\circ} \mathrm{C}$ (unless declared otherwise) for 7 to 11 days. Conversion, yield, and diastereomeric selectivity were determined using RP-18 HPLC (procedure described in chapter 5.2). For catalytic tests using dried sample, UiO-67-NHPro (93 mg, $0.20 \mathrm{mmol}$ regarding to amount of proline in UiO-67-NHPro) was directly soaked with mixture of starting materials. For each reaction $5 \mathrm{ml}$ of solvent were used. Catalysts used with direct stirring were placed directly in a culture tube and stirred with a stirring bar.

Catalysis with UiO-68-NHPro: Three batches of UiO-68-NHPro (approximately $70 \mathrm{mg}, 0.13 \mathrm{mmol}$ regarding to the amount of proline) were combined and washed with ethanol ( $3 \times 5 \mathrm{ml})$. In analogy to catalytic tests performed with UiO-67-NHPro, the material was transferred in a glass tube with a stirring bar on top, which was placed in a culture tube. 4-Nitrobenzaldehyde (98.2 $\mathrm{mg}, 0.65 \mathrm{mmol}$ ) was solved in ethanol $(5.0 \mathrm{~mol})$ and mixed with the MOF. Cyclohexanone $(638 \mathrm{mg}, 6.50 \mathrm{mmol})$ was added dropwise and the reaction was stirred at $40{ }^{\circ} \mathrm{C}$ for $7-11$ days. Conversion, yield and diastereomeric selectivity were determined using HPLC (procedure described in chapter 5.2). For catalysis with dried material UiO-68-NHPro $(70 \mathrm{mg}, 0.13 \mathrm{mmol})$ was soaked in mixture of starting materials in $5 \mathrm{ml}$ solvent. Direct stirring was performed without screwed glass tube with direct mixing of the stirring bar in the MOF.

Catalysis with $\mathrm{Me}_{2}$ bpdc-NHPro: For homogeneous catalysis, Me $\mathrm{e}_{2}$ bpdc-NHPro (76 mg, $0.20 \mathrm{mmol}$ ) and 4-nitrobenzaldehyde (151 mg, $1 \mathrm{mmol}$ ) were dissolved in dry solvent $(5 \mathrm{ml}$ of EtOH, heptane, DMSO or DCM). After stirring of $20 \mathrm{~min}$ cyclohexanone (982 $\mathrm{mg}, 10 \mathrm{mmol}$ ) was added dropwise and the solution was stirred at $40{ }^{\circ} \mathrm{C}$ for 7-11 days. Conversion, yield and diastereomeric selectivity 
were determined using HPLC (procedure described in chapter 5.2). For isolation of products reaction solution was washed with saturated ammonium chloride solution $(15 \mathrm{ml})$. The aqueous solution was extracted with ethyl acetate $(3 \times 10 \mathrm{ml})$ and the organic parts were combined. The resulting organic solution was dried using magnesium sulfate and the solvent was removed under reduced pressure. The raw product was further purified by flash chromatography (eluent: ethyl acetate/n-hexane, $2 / 1$ ). Two product phases could be isolated, whereby the first phase contains syn-/anti-adduct mixture with a 50/50-ratio. Second phase consists of syn-/anti-adduct ratio of 7/93. Ratios were examined using liquid ${ }^{1} \mathrm{H} N M R$ analysis in $\mathrm{CDCl}_{3}$. Both mixtures were used for signal assignment in HPLC analysis.

\section{2) Development of HPLC analysis procedure for catalysis}

Diastereomers were separated using nonchiral HPLC column (RP-18). Following parameters were optimized for baseline separation:

- column: LICHROSPHER ${ }^{\circledR} 100$ RP-18, 250 mm (LICHROCART ${ }^{\circledast}$,MERCK MILLIPORE)

- wavelength: $220 \mathrm{~nm}$

- mobile phase: acetonitrile/water (35/65)

- flow: $0.8 \mathrm{ml} \mathrm{min}{ }^{-1}$

- $\mathrm{t}_{R}($ anti-adduct $)=19.5 \mathrm{~min}, \mathrm{t}_{R}($ syn-adduct $)=22.0 \mathrm{~min}$

Signal assignment for HPLC was investigated using product samples of homogeneous catalysis after isolation by flash chromatography, as described before in chapter 5.1 "Catalysis with $\mathrm{Me}_{2}$ bpdcNHPro" of ESI. By flash chromatography several product phases could be isolated, whereby the syn/anti- ratio of the diastereomers are different. Two of these phases are used in the following to identify signal-assignment in HPLC. The two product mixtures were analyzed by liquid ${ }^{1} \mathrm{H}$ NMR analysis in $\mathrm{CDCl}_{3}$, whereby identification of the diastereomers was achieved by comparison with described NMR results from literature ${ }^{2-4}$. In Figure S.6 results for HPLC measurement and liquid ${ }^{1} \mathrm{H}$ NMR analysis of syn-/anti-mixture of $7 / 93$ are shown, whereby Figure S.7 shows analogue investigations of a 50/50-mixture of both diastereomers. The results allow a clear assignment of HPLC-signals for both diastereomers. 


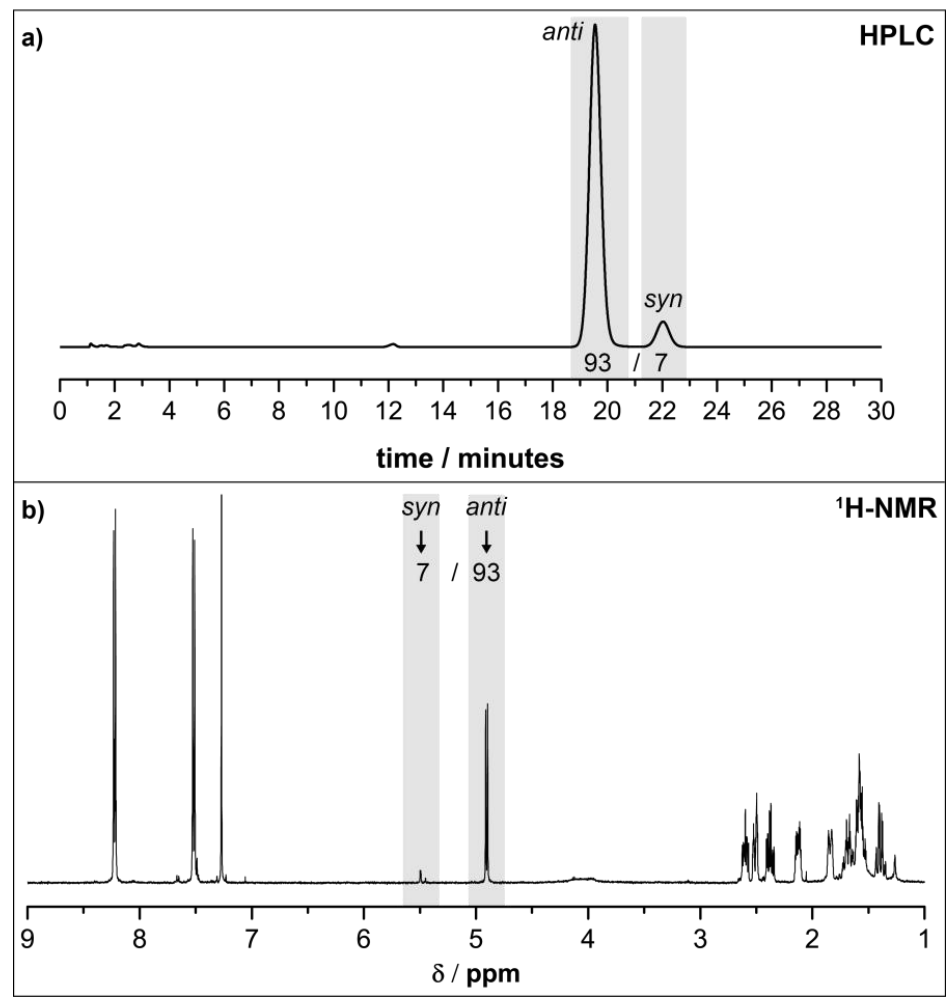

Figure S.6 Signal assignment of syn- and anti-adduct in HPLC using identical mixture of synand anti-adduct in 7/93 ratio (from homo-catalytic test, see ESI 5.1) for HPLC and liquid ${ }^{1} \mathrm{H}$ NMR.

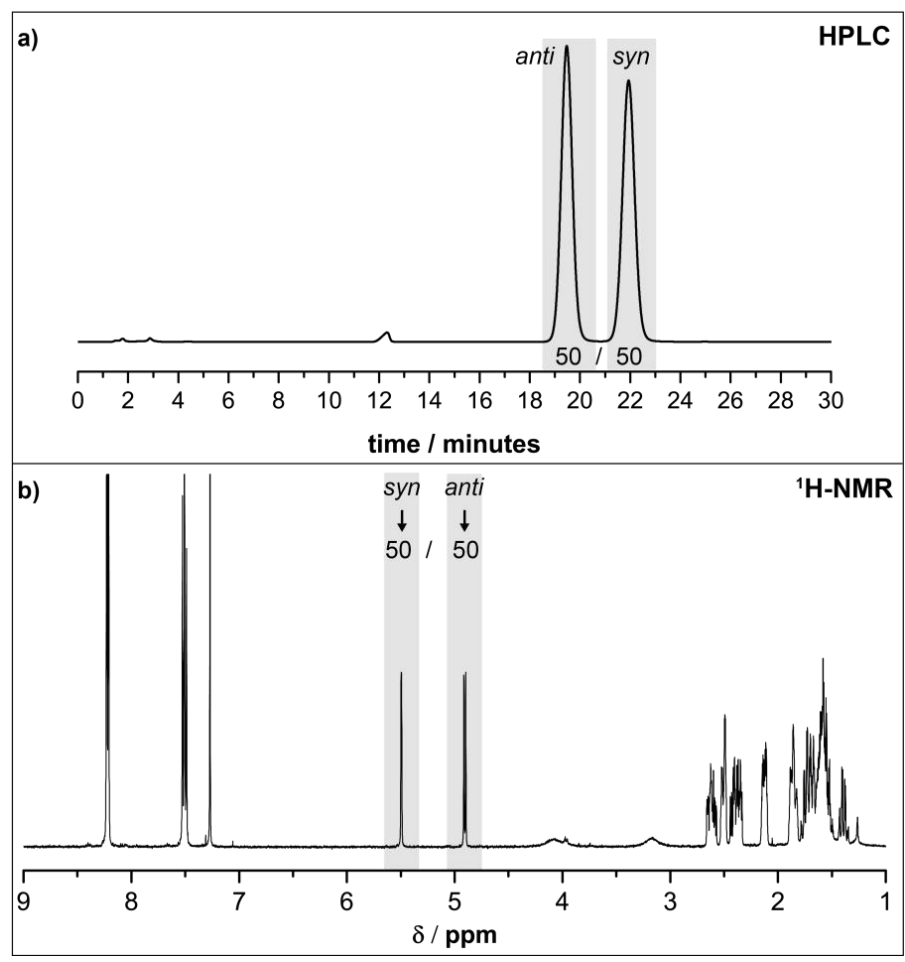

Figure S.7 Signal assignment of syn- and anti-adduct in HPLC using identical mixture of synand anti-adduct in 50/50 ratio (from homo-catalytic test, see ESI 5.1) for HPLC and liquid ${ }^{1} \mathrm{H}$ NMR. 
For further preliminary investigations para-nitrobenzaldehyde (para-NB) and a mixture of paranitrobenzaldehyde and product phase (7/93, syn-/anti-adduct) was measured by HPLC with described parameters on RP-18 column. Baseline separation of starting material and the diastereomers could be achieved, see Figure S.8.

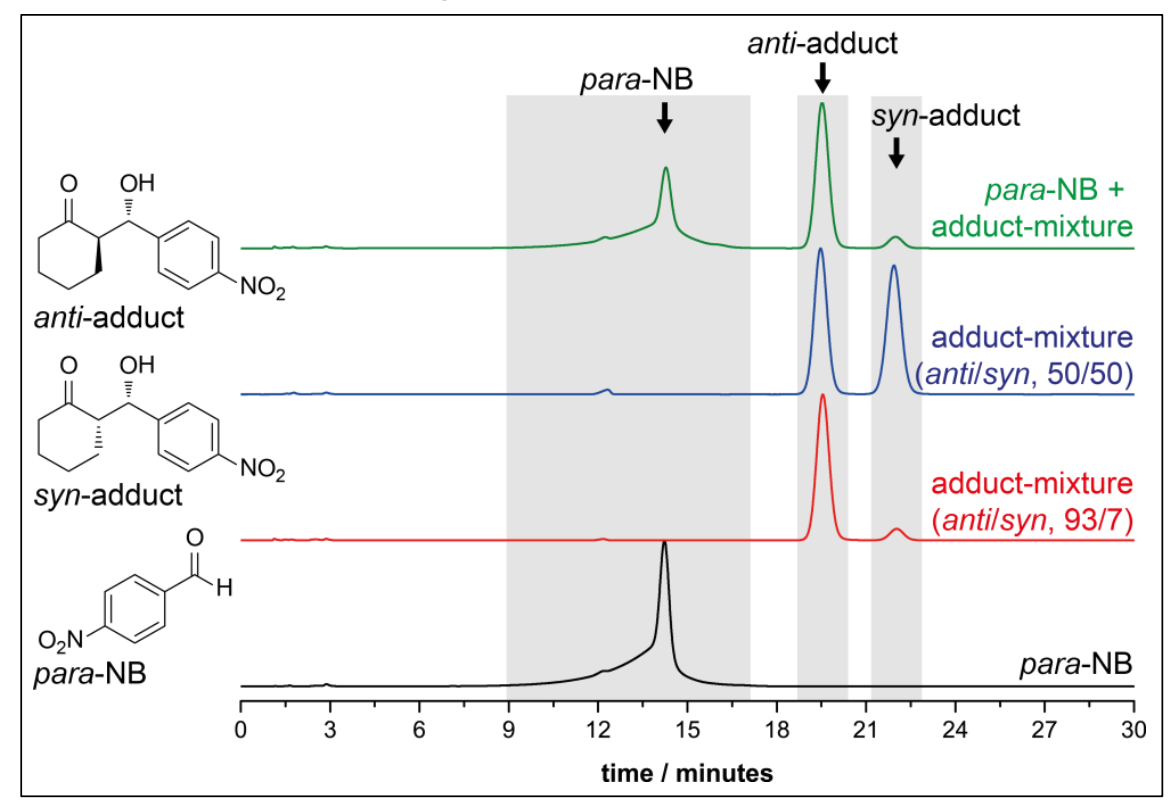

Figure S.8 HPLC measurements of para-nitrobenzaldehyde (para-NB), product mixtures and mixture of para-NB with product mixture (7/93, syn-/anti-adduct) with nonchiral RP-18 column.

In Figure S.9 examples of HPLC-results before and after typical catalysis with UiO-67-NHPro (Figure S.9-a) and UiO-68-NHPro (Figure S.9-b) are shown. The chromatograms of the starting solution only show para-NB signals and signal of injected solvent-media. The chromatogram after catalysis of 10 days with UiO-67-NHPro indicates a significant amount of para-NB $161 \%$ of initial concentration). Furthermore, higher amount of syn-adduct is detected resulting in a syn-/anti-ratio of 79/21. In contrast, chromatogram of catalysis with UiO-68-NHPro after 10 days shows a nearly complete conversion of para-NB (3\% left of initial concentration). Syn-/anti-ratio is also increased up to $88 / 12$. 


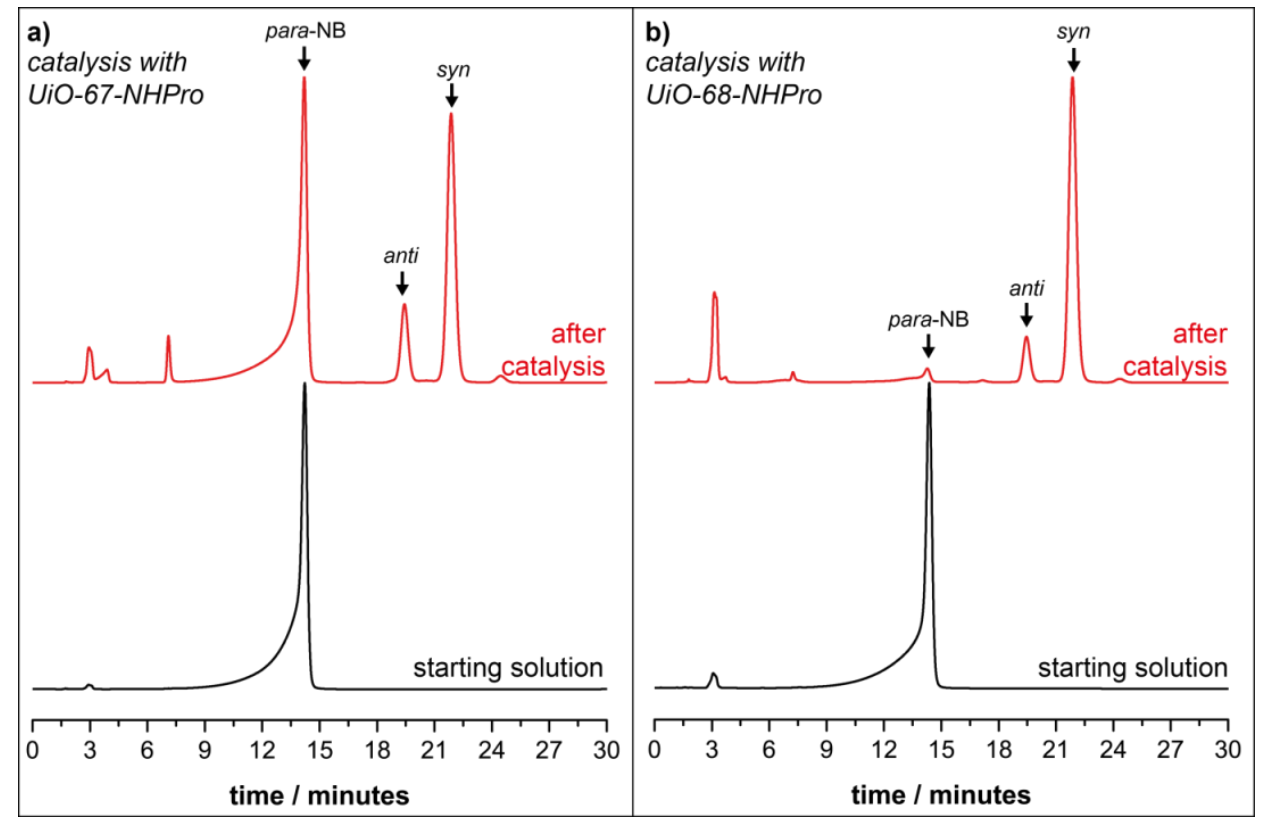

Figure S.9 HPLC chromatograms of catalysis solutions before and after catalysis of 10 days with UiO-67-NHPro (a) and UiO-68-NHPro (b). HPLC procedure and signal assignment was performed as described before in 5.2, ESI.

\section{3) Calibrations for quantitative investigations}

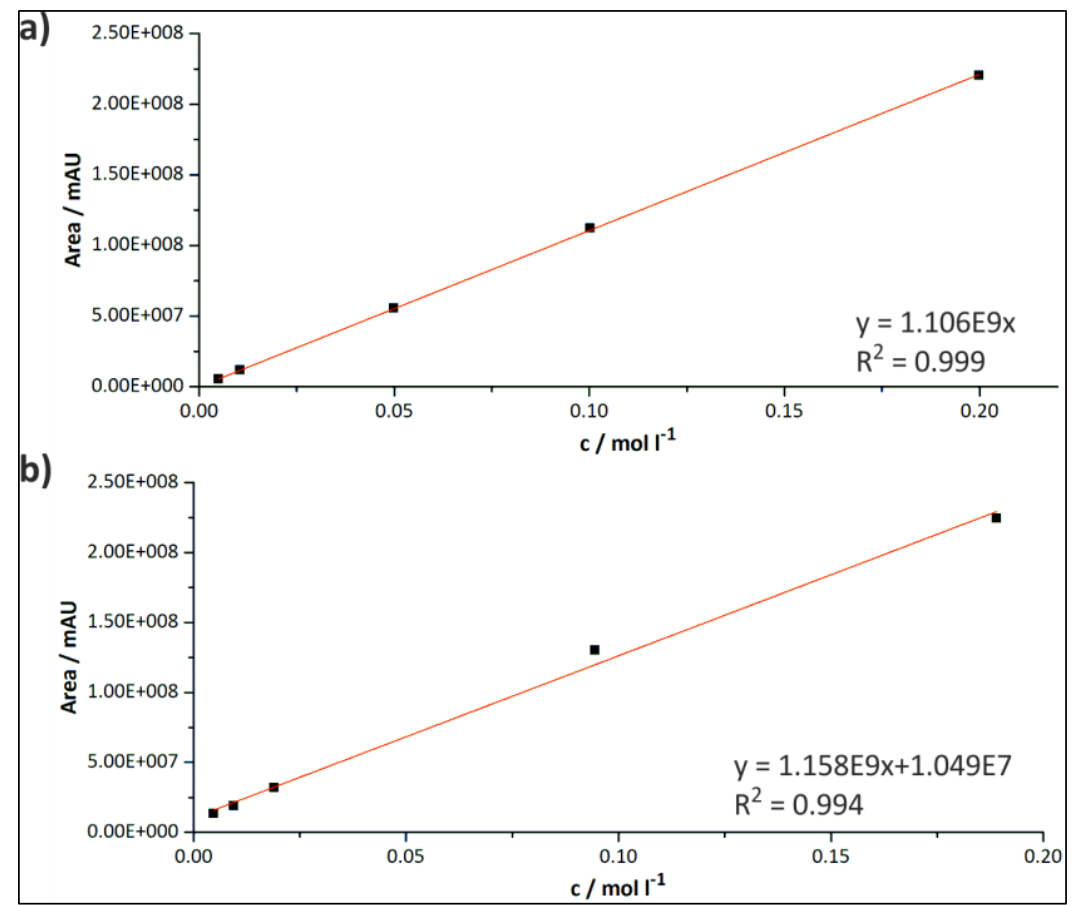

Figure S.10 Calibration curves of a) 4-nitrobenzaldhyde and b) aldol adduct of performed aldol addition. 
For conversion and yield determination, calibrations using starting material 4-nitrobenzaldehyde and the aldol adduct were performed (see Figure S.10). Quantitative evaluation was performed using nonchiral HPLC with the method described before. For determination of product amount area-sum of both diastereomers was used. The aldol adducts were collected during several catalysis tests with UiO-67-NHPro. The combined raw-product phases were purified by flash chromatography (hexane/ethyl acetate, $1 / 2$ ) to obtain pure product phase for calibration. The purity of the product was tested by HPLC and ${ }^{1} \mathrm{H}$ NMR studies.

\section{4) ee-value determination}

For determination of enantiomeric excess (ee) by chiral HPLC, the samples obtained from catalytic reaction (described in chapter 5.1) were pretreated in the following way: Reaction solution was washed with saturated, aqueous ammonium chloride solution. The mixture was extracted by ethyl acetate $(3 \times 30 \mathrm{ml})$ and the combined organic phases were washed with deionized water $(2 \times 50 \mathrm{ml})$. The organic solution was dried over $\mathrm{MgSO}_{4}$ and the solvent was removed by evaporation. The raw product was further purified by flash chromatography in ethyl acetate/ $n$-hexane mixture $(1 / 1.1)$ to obtain pure product phase without 4-nitrobenzaldehyde.

Enantiomers were separated using chiral HPLC column for normal phase separation. Following parameters were optimized for baseline separation:

- column: LUX ${ }^{\circledR} 5 \mu \mathrm{m}$ Amylose-1, 250x4.6 mm (PHenOMEneX)

- wavelength: $250 \mathrm{~nm}$

- mobile phase: $n$-hexane/2-propanol (85/15)

- flow: $0.8 \mathrm{ml} \mathrm{min}^{-1}$

- $\mathrm{t}_{R}($ syn- 1$)=17.2 \pm 0.1 \mathrm{~min}, \mathrm{t}_{R}($ syn- 2$)=20.1 \pm 0.1 \mathrm{~min}, \mathrm{t}_{R}($ anti- 1$)=22.0 \pm 0.1 \mathrm{~min}, \mathrm{t}_{R}($ anti- 2$)=$ $29.5 \pm 0.2 \mathrm{~min}$

Figure S.11 shows two chromatograms obtained from chiral HPLC measurements. The analytes were purified by the described method. Signals were assigned to diastereomer species by previous nonchiral HPLC analysis of the same sample, whereby ratios between syn- and anti-adduct were compared to ratios in chiral HPLC results. Information about area integration results and resulting ee-values are listed in Table S.1. 

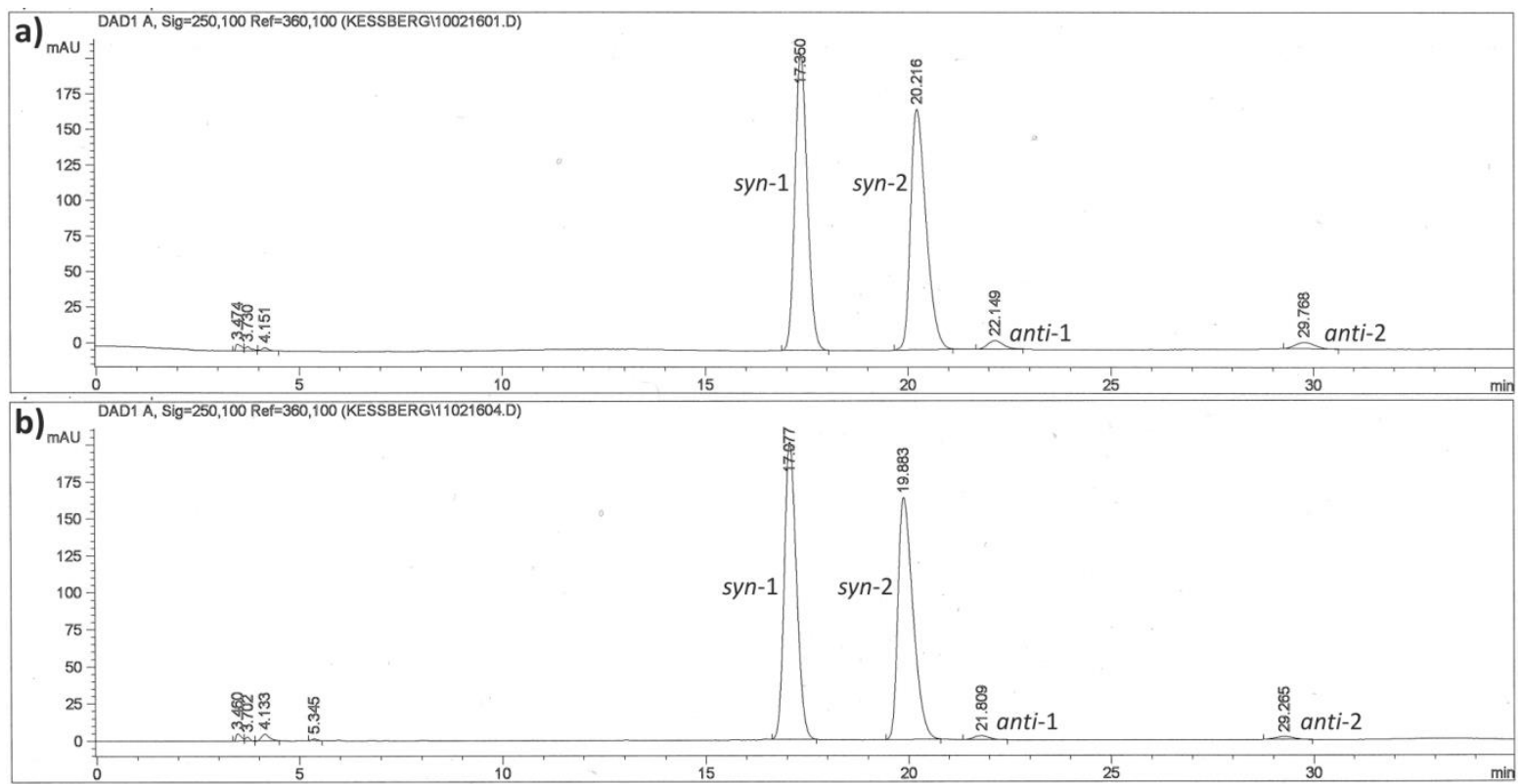

Figure S.11 HPLC-chromatograms of catalysis products after purification of: a) catalysis with UiO-67-NHPro and b) catalysis with UiO-68-NHPro. The annotation of the signals belong to the retention time.

Table S.1 Data obtained by chiral HPLC measurements of four catalytic reactions using UiO-67NHPro or UiO-68-NHPro, following the reaction procedure of chapter 5.1.

\begin{tabular}{cccc}
\hline Sample & Area (syn-1) [\%] & Area (syn-2) [\%] & ee-value [\%]* \\
\hline Catalysis 1 @ UiO-67-NHPro & 47.3246 & 48.1145 & 0.8 \\
Catalysis 2 @ UiO-67-NHPro & 39.1651 & 40.2337 & 1.3 \\
Catalysis 1 @ UiO-68-NHPro & 48.3319 & 48.4603 & 0.1 \\
Catalysis 2 @ UiO-68-NHPro & 31.8944 & 32.0495 & 0.2
\end{tabular}

*For ee-value calculation, area\% values of the main diastereomer (syn) were used in following

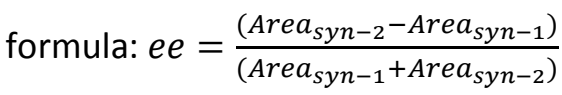

In Table S.1 results of chiral HPLC measurements are summarized. The resulting ee-values (0 - 1.3\%) can be assigned to be within the error range of the measurements.

\section{5) Comparison of stirring conditions}

For catalytic tests with UiO-67-NHPro and UiO-68-NHPro indirect stirring method was developed to prevent material decomposition due to mechanical stress by direct contact with the stirring bar. Therefore a screwed glass vial $(32 \times 11.6 \mathrm{~mm})$ filled with solid catalyst was placed in a culture tube 
(16 $\times 100 \mathrm{~mm}$ ). On top of the screwed glass vial a small triangular stirring bar was placed to ensure complete mixing of the reaction solution (see Figure S.12).

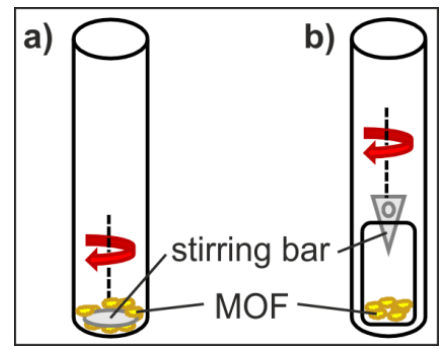

Figure S.12 Illustration of stirring conditions during catalysis reaction. a) Direct stirring by the stirring bar in the reaction mixture. b) Indirect stirring.

Kinetic studies of catalyst performance depending on stirring conditions were investigated using UiO-67-NHPro and UiO-68-NHPro (see Figure S.13). In comparison to solvent studies for kinetic investigations ethanol was used as solvent. Comparison of the kinetic curves recorded under different stirring conditions shows, that direct stirring is more efficient giving slightly higher conversion rates. The general trend of the catalysis development remains the same. Consequently, direct stirring can reduce reaction time.

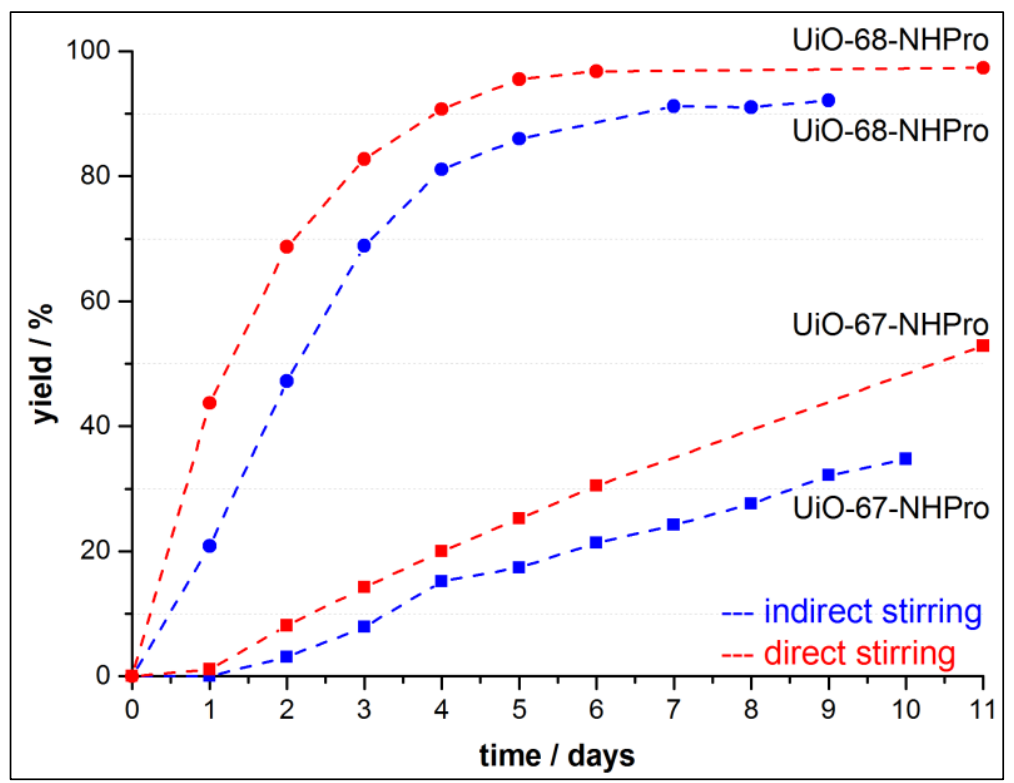

Figure S.13 Kinetic curves obtained using UiO-67-NHPro and UiO-68-NHPro as catalysts under different stirring conditions. The yield was determined by HPLC measurements.

To study the influence of stirring conditions on catalyst stability, cycleability studies were performed. After each cycle, the MOFs were washed with ethanol $(5 \times 5 \mathrm{ml})$ to remove residual starting materials and products from the pores. Figure S.14 shows yields and de-value development 
depending on stirring conditions, indicating that indirect stirring is advantageous as lower yield decrease is observed after 3 cycles. These results indicate also a low resistance of chiral UiO compounds against mechanical stress. Therefore, indirect stirring was preferably used for catalytic investigations to prevent mechanical degradation of the crystals.

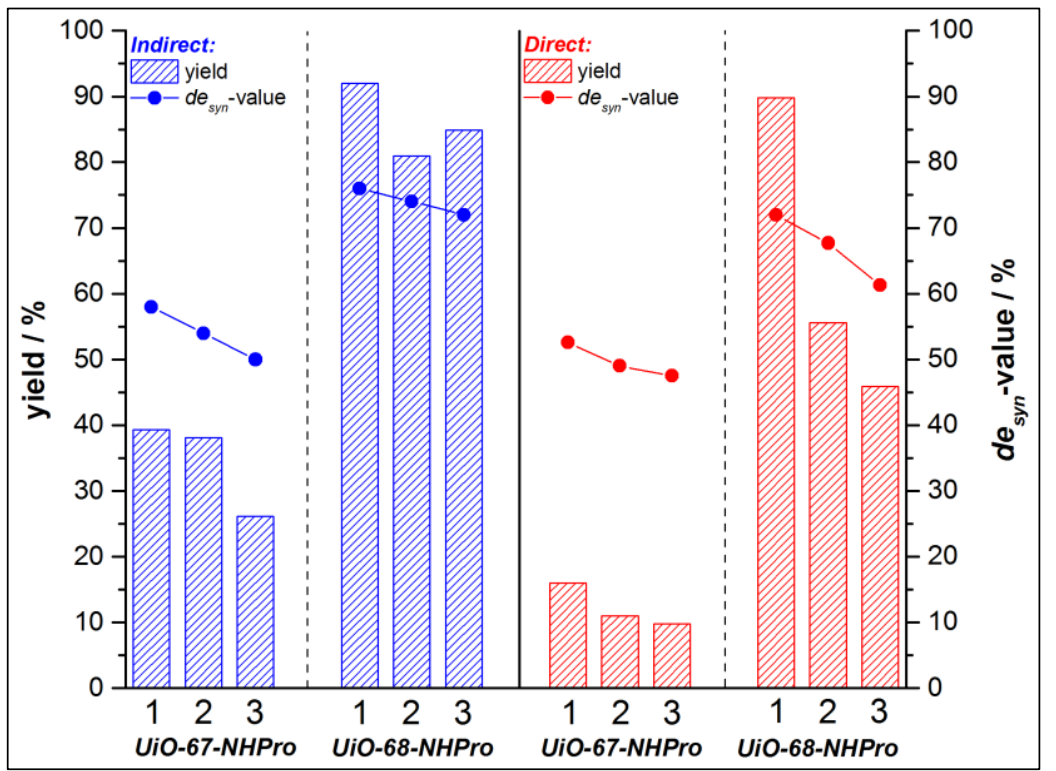

Figure S.14 Cyclic catalytic asymmetric aldol addition experiments with UiO-67-NHPro and UiO68-NHPro using direct (red) and indirect (blue) stirring conditions. Standard reaction conditions were used, except for the reaction time (indirect $-11 d$, direct $-3 d$ ).

For physisorption experiments the MOFs before (as made) and after catalysis (direct or indirect stirring) were washed several times with ethanol during 14 days and subjected to the supercritical $\mathrm{CO}_{2}$ drying. $\mathrm{N}_{2}$ physisorption isotherms after catalysis show low decrease in nitrogen uptake in case of UiO-67-NHPro (see Figure S.15a). The samples subjected to the indirect stirring during the catalysis and washing process show lowest porosity. These results correlate with the results of cyclic catalyst experiments (see Figure S.14), whereas constant loss of catalyst activity with increasing number of cycles was observed. For UiO-68-NHPro, a drastic decrease of $70 \%$ in nitrogen uptake after indirect stirring is observed, indicating high degree of pore blocking in the outer shell of large crystals. Cycling tests showed only low fluctuation in reaction yield (see Figure S.14). Direct stirring of the catalysis shows only low decrease in porosity, whereas cycling tests show significant decrease in yield during 3 cycles indicating mechanical stress-induced deterioration. 


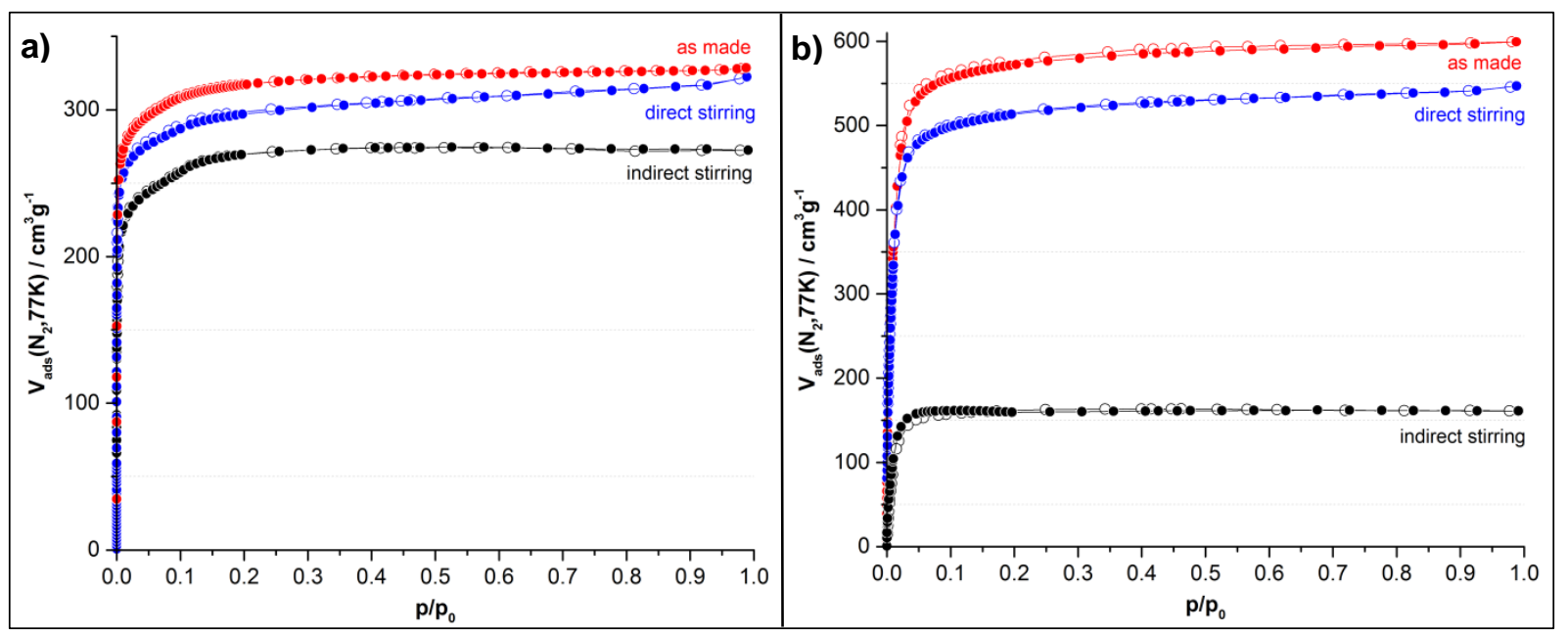

Figure S.15 $\quad \mathrm{N}_{2}$ physisorption measurements on UiO-67-NHPro (a) and UiO-68-NHPro (b) MOFs before (red curve) and after catalysis with direct (blue curve) and indirect (black curve) stirring. Adsorption - filled circles, desorption - empty circles.

Despite the fact that the catalyst shows an intensified yellow-orange color from product residues, liquid ${ }^{1}$ H NMR studies of the digested MOF could not detect any products. Typical signals of aldol adduct or additional signals could not be detected. For direct aldol addition of cyclohexanone and 4-nitrobenzaldehyde with L-proline, side product formation of 1-oxapyrrolyzidine or other oxazolidinone species especially in anhydrous solvents has been reported. ${ }^{5,6}$ These side products are derivatives of proline with the aldehyde of the reaction mixture. The formation of such species in case of UiO-67-NHPro could be ruled out by ${ }^{1} \mathrm{H}$ NMR analysis. Furthermore, to enable the formation of oxazolidinone or oxapyrrolyzidine species, the carboxylic acid group of proline should be involved. In case of UiO-67-NHPro and UiO-68-NHPro this carboxylic acid group, however, participates in an amide bond. Consequently, the typical side product formation of oxazolidinones and the daughter product 1-oxapyrrolyzidine is not possible. On basis of this discussion, this type of derivatization on proline side group cannot be expected. All in all the linkers after MOF synthesis stayed intact. Liquid ${ }^{1}$ H NMR analysis confirms linker backbone with stoichiometric amount of coupled proline. Therefore decoupling of proline from the linker backbone can be ruled out.

PXRD measurements of all MOF samples before and after catalysis show, that crystallinity of UiO67-NHPro and UiO-68-NHPro is not significantly affected by catalytic runs (Figure S.16). 

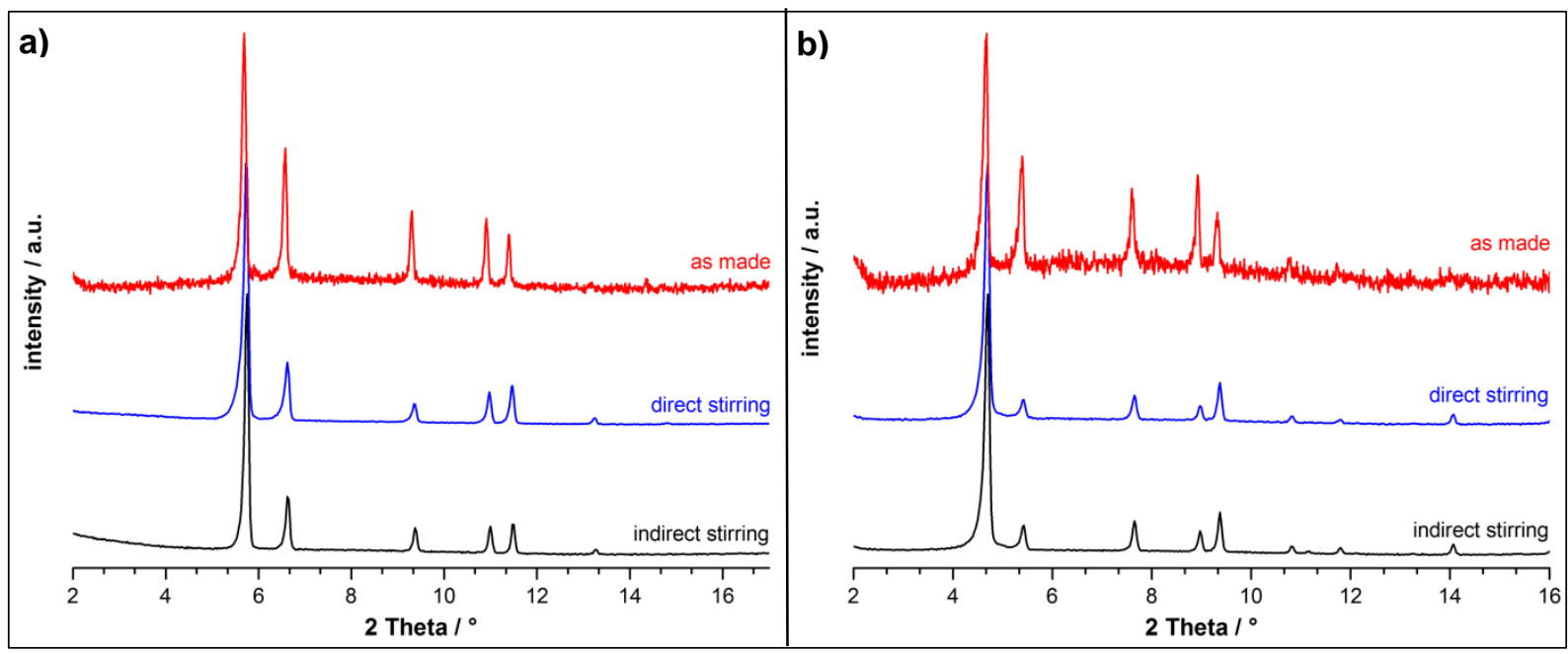

Figure S.16 PXRD pattern of the catalysts before (red curve) and after catalysis with direct (blue curve) and indirect (black curve) stirring: a) for UiO-67-NHPro; b) for UiO-68-NHPro.

\section{6) Leaching tests}

To ensure heterogeneous character of the catalysts, filtration tests were performed. Therefore, standard catalysis process was started using UiO-67-NHPro and UiO-68-NHPro under direct stirring. After one day, the MOFs were removed from the reaction mixture using PTFE syringe filters $(\varnothing=13 \mathrm{~mm}$, pore sizes $=0.22 \mu \mathrm{m})$ and the filtrate was stirred for several days at $40{ }^{\circ} \mathrm{C}$. After each $24 \mathrm{~h} \mathrm{HPLC}$ measurement was performed to investigate yield development after removal of the catalyst (see Figure S.17). The first HPLC measurement (1 day) was performed directly after filtering. Both curves show no increase of the yield after catalyst removal, proving heterogeneity of the catalysts.

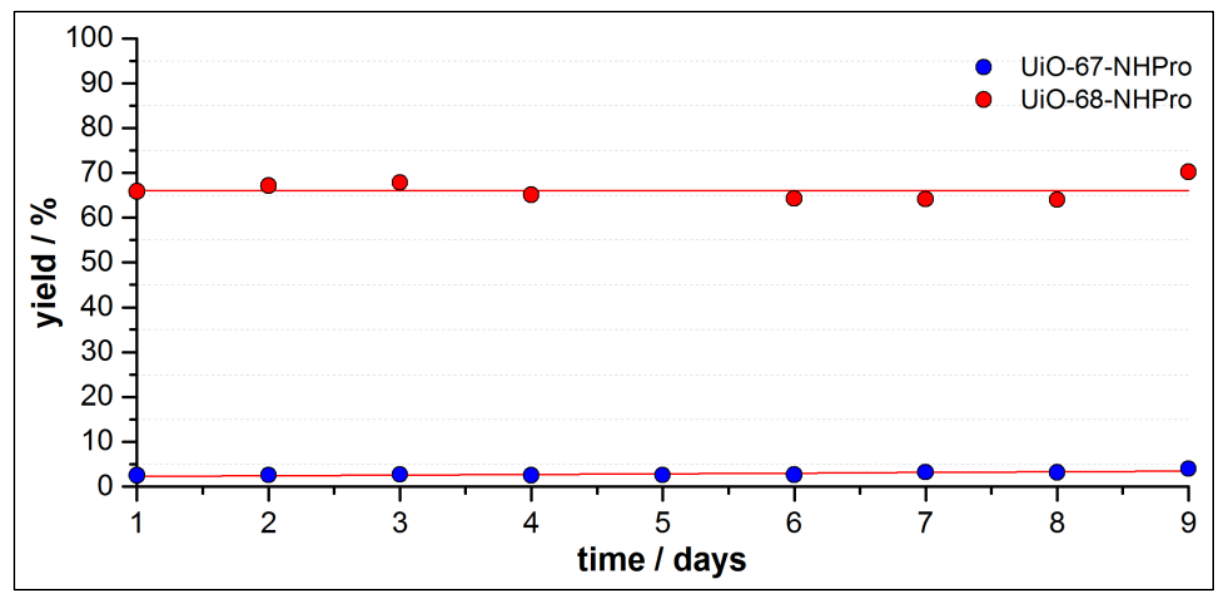

Figure S.17 Filtration tests for reactions catalyzed for $24 \mathrm{~h}$ by UiO-67-NHPro (blue dots) and UiO-68-NHPro (red dots). 


\section{Crystallographic data for UiO-68-NHPro}

Octahedral single crystal of UiO-68-NHPro was prepared in a glass capillary with $0.3 \mathrm{~mm}$ wall thickness with some amount of DMF. The capillary was sealed with melted wax. The datasets were measured at BESSY MX BL14.2 beamline of HZB. ${ }^{7}$ All diffraction experiments were performed at room temperature using the radiation with energy of $14 \mathrm{keV}(\lambda=0.88561 \AA)$. The $\phi$-scans with oscillation range of $1^{\circ}$ were used for data collection. The datasets were processed using CCP4 software. ${ }^{8}$ Both crystal structures were solved by direct methods and refined by full matrix leastsquares on $F^{2}$ using SHELXTL program package. ${ }^{9}$ Due to the presence of the chiral center in the compound, the chiral space group F23 was used for the structure solution and refinement, although centrosymmetric $F m \overline{\mathbf{3}} m$ space group was suggested from diffraction data. ${ }^{10}$ All nonhydrogen atoms were refined in anisotropic approximation. Hydrogen atoms were refined in geometrically calculated positions using "riding model" with $U_{\text {iso }}(H)=1.2 U_{\text {iso }}(C)$. The middle phenyl ring of the ligand molecule is disordered over two positions: C10, C11 and C9, C12. These atoms were refined with occupancy of 0.5 . Although the residual electron density for the chiral L-proline group is indubitably present, it could not be properly modelled because of the strong rotational disorder as well as low occupancy of each position. Solely the nitrogen atom, directly connected to the phenyl ring and disordered over 8 positions with $12.5 \%$ occupancy of each, could be nevertheless unambiguously refined in isotropic approximation. Other atoms from L-proline substituent as well as lattice solvent molecules could not be localized from the difference Fourier map. CCDC-1419929 contains the supplementary crystallographic data for UiO-68-NHPro. These data can be obtained free of charge from the Cambridge Crystallographic Data Centre via www.ccdc.cam.ac.uk/data_request/cif.

Crystal data for UiO-68-NHPro: $\mathrm{C}_{120} \mathrm{H}_{48} \mathrm{~N}_{6} \mathrm{O}_{32} \mathrm{Zr}_{6}, \mathrm{M}=2632.96 \mathrm{~g} \mathrm{~mol}^{-1}$, cubic, F23, $a=32.880(4) \AA$, $V=35546(7) \AA^{3}, Z=4, \rho_{\text {calc }}=0.492 \mathrm{~g} \mathrm{~cm}^{-3}, \lambda=0.88561 \AA, T=296 \mathrm{~K}$, reflections collected/unique $41593 / 6782, R_{1}=0.0571, w R_{2}=0.2780, S=2.754$, largest diff. peak 2.162 e $\AA^{-3}$ and hole 1.308 e $\AA^{-3}$. 


\section{Pawley refinement of the unit cell for UiO-67-NHPro}

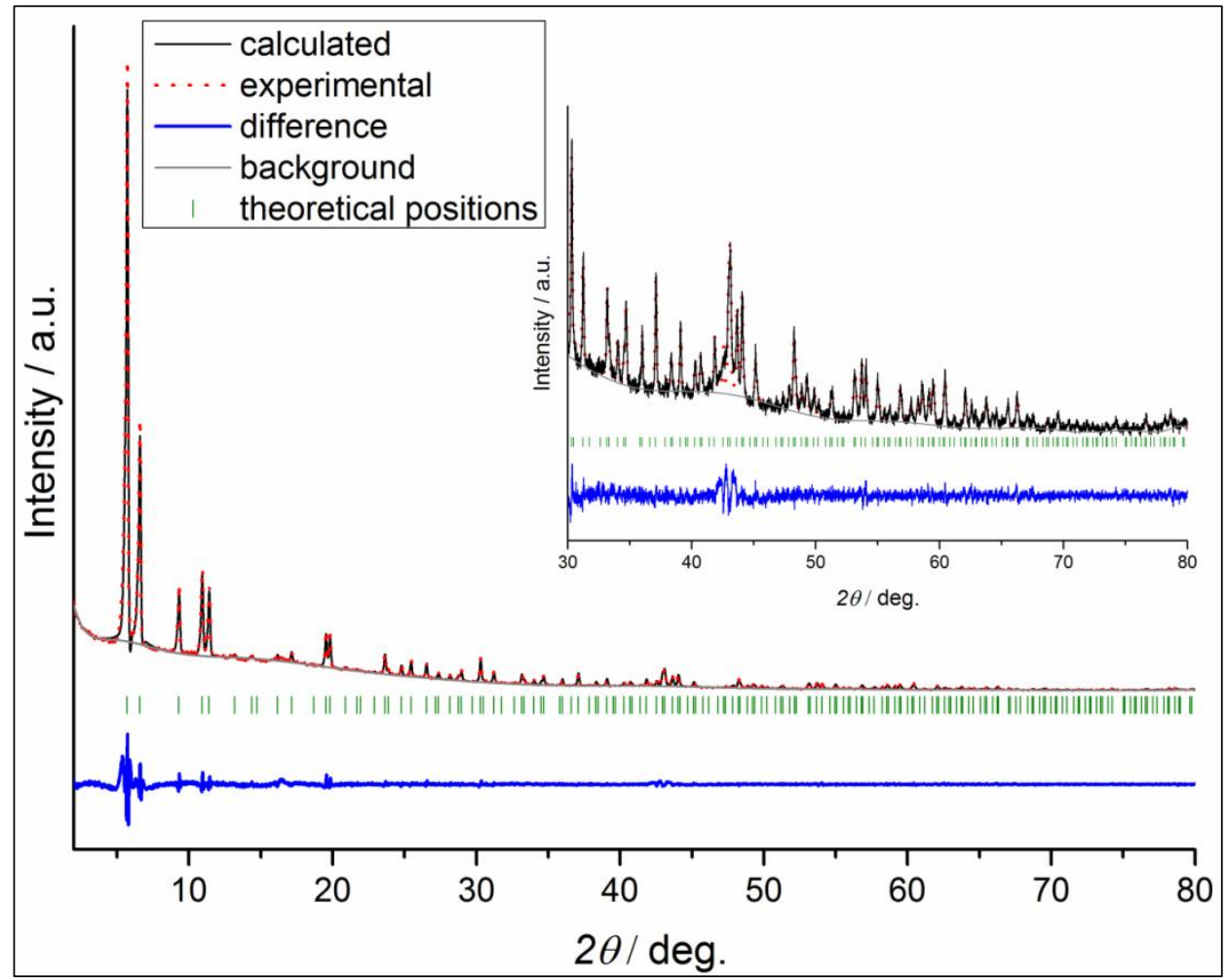

Figure S.18 Pawley plot for UiO-67-NHPro.

Summary report for Pawley refinement of UiO-67-NHPro: $2 \vartheta$ range $2-80^{\circ}$, radiation $\mathrm{Cu}-K_{\alpha 1}$ $(\lambda=1.5406 \AA)$, number of peaks 552 , cubic $F, a=26.8663(1) \AA$, Profile function pseudo-Voigt, $U=0.33912, V=-0.16689, W=0.04481$, Transmission geometry, zero line shift $-0.00991^{\circ}$, Asymmetry correction Berar-Baldinozzi, $P 1=1.33(1), P 2=-0.036(3), P 3=-2.92(3), P 4=0.022(6)$. 


\section{References}

(1) Kutzscher, C.; Hoffmann, H. C.; Krause, S.; Stoeck, U.; Senkovska, I.; Brunner, E.; Kaskel, S. Proline Functionalization of the Mesoporous Metal-Organic Framework DUT-32. Inorg. Chem. 2015, 54, 1003-1009.

(2) Kanemitsu, T.; Umehara, A.; Miyazaki, M.; Nagata, K.; Itoh, T. L-t-Leucine-Catalyzed Direct Asymmetric Aldol Reaction of Cyclic Ketones. European J. Org. Chem. 2011, 993-997.

(3) Kofoed, J.; Darbre, T.; Reymond, J.-L. Artificial aldolases from peptide dendrimer combinatorial libraries. Org. Biomol. Chem. 2006, 4, 3268-3281.

(4) Luo, S.; Xu, H.; Li, J.; Zhang, L.; Cheng, J. P. A simple primary-tertiary diamine-Brønsted acid catalyst for asymmetric direct aldol reactions of linear aliphatic ketones. J. Am. Chem. Soc. 2007, 129, 3074-3075.

(5) Zotova, N.; Franzke, A.; Armstrong, A.; Blackmond, D. G. Clarification of the role of water in proline-mediated aldol reactions. J. Am. Chem. Soc. 2007, 129, 15100-15101.

(6) Penhoat, M.; Barbry, D.; Rolando, C. Direct asymmetric aldol reaction co-catalyzed by Lproline and group 12 elements Lewis acids in the presence of water. Tetrahedron Lett. 2011 $52,159-162$.

(7) Mueller, U.; Darowski, N.; Fuchs, M. R.; Förster, R.; Hellmig, M.; Paithankar, K. S.; Pühringer, S.; Steffien, M.; Zocher, G.; Weiss, M. S. Facilities for macromolecular crystallography at the Helmholtz-Zentrum Berlin. J. Synchrotron Radiat. 2012, 19, 442-449.

(8) Winn, M. D.; Ballard, C. C.; Cowtan, K. D.; Dodson, E. J.; Emsley, P.; Evans, P. R.; Keegan, R. M.; Krissinel, E. B.; Leslie, A. G. W.; McCoy, A.; McNicholas, S. J.; Murshudov, G. N.; Pannu, N. S.; Potterton, E. A.; Powell, H. R.; Read, R. J.; Vagin, A.; Wilson, K. S. Overview of the CCP 4 suite and current developments. Acta Crystallogr. Sect. D Biol. Crystallogr. 2011, 67, 235242.

(9) Sheldrick, G. M. A short history of SHELX. Acta Crystallogr. Sect. A Found. Crystallogr. 2008, 64, 112-122.

(10) Spek, A. L. Structure validation in chemical crystallography. Acta Crystallogr. Sect. D Biol. Crystallogr. 2009, 65, 148-155. 